\title{
Remote sensing of selective logging in tropical forests: current state and future directions
}

\author{
Colbert M Jackson, \\ Elhadi Adam
}

\begin{abstract}
This paper reviews and discusses the status of remote sensing techniques applied in detecting and monitoring selective logging disturbance in tropical forests. The analyses concentrated on the period 1992-2019. Accurate and precise detection of selectively logged sites in a forest is crucial for analyzing the spatial distribution of forest disturbances and degradation. Remote sensing can be used to monitor selective logging activities and associated forest fires over tropical forests, which otherwise requires labor-intensive and time-consuming field surveys, that are costly and difficult to undertake. The number of studies on remote sensing for selective logging has grown steadily over the years, thus, the need for their review so as to guide forest management practices and current research. A variety of peer reviewed articles are discussed so as to evaluate the applicability and accuracy of different methods in different circumstances. Major challenges with existing approaches are singled out and future needs are discussed.
\end{abstract}

Keywords: Tropical Forest Disturbance, Selective Logging, Forest Degradation, Forest Canopy Gaps, Disturbance Mapping, Remote Sensing, Forest Monitoring

\begin{abstract}
Introduction
Tropical forests are responsible for their biological diversity (Da Ponte et al. 2015), housing more than half of the diversity of life on Earth and offering several vital biological applications (Solberg et al. 2008). Tropical forests regulate global weather patterns, and more importantly, play a key role in the global carbon cycle (Da Ponte et al. 2015), keeping large amounts of carbon and producing great supplies of the Earth's oxygen (Solberg et al. 2008). Tropical forests and the land they occupy support numerous indigenous cultures and peoples (Solberg et al. 2008). Despite the remarkable values and functions of tropical forests, many conservation and protection efforts have not been effective, as a result those forests are being cleared in many
\end{abstract}

$\square$ School of Geography, Archaeology and En vironmental Studies, University of the Witwatersrand, Johannesburg, Private Bag 3 Wits, 2050 (South Africa)

@ Colbert M Jackson

(mutisojackson@yahoo.com)

Received: Nov 25, 2019 - Accepted: May 11, 2020

Citation: Jackson CM, Adam E (2020). Remote sensing of selective logging in tropical forests: current state and future directions. iForest 13: 286-300. - doi: 10.3832/ifor3301-013 [online 2020-07-10]

Communicated by: Emanuele Lingua countries so as to harvest the timber and exploit the land in various ways (Gibson et al. 2011). Forest disturbance from selective logging and associated degradation by forest fires may have enduring effects on forest dynamics and composition (Asner et al. 2006), thus interfering with forest health and the availability of essential ecosystem functions and services (Gibson et al. 2011). A study in the Brazilian Amazon showed an increase in total forested areas affected by selective logging and forest fires from approximately 11,800 to $35,600 \mathrm{~km}^{2}$ in 1992 and 1999, respectively (Matricardi et al. 2013). Asner et al. (2005) discovered that each year, selective logging can expand over as much forested area as does deforestation, with logged areas ranging in size from 12,075 to $19,823 \mathrm{~km}^{2}$ between 1999 and 2002. The study showed that between 1999 and 2004 , about $76 \%$ of all timber harvest practices led in high levels of canopy damage sufficient to leave forests prone to drought and fire (Asner et al. 2005). Currently, few truly undisturbed tropical forests exist, and arguably the single most important cause of tropical forest degradation worldwide is unsustainable selective logging (Miettinen et al. 2014). More than 400 million hectares of natural tropical forests have been degraded since 1980 (Edwards et al. 2014). Selective logging is a form of extraction of timber where a group of trees from selected species, the high-value tree species, are removed from the forest (Andersen et al. 2014). Global demand for precious and rare tropical timber, such as ebony and rosewood, is expected to continue to grow, and the international market has approximately 50-90\% of tropi- cal wood harvested illegally (Nellemann 2012). Thus, there is the need for sustainable forest management (SFM). SFM is the process of managing a forest so as to reduce forest degradation and deforestation by ensuring the sustainability of forest resources, protection and conservation of genetic diversity and to ensure the sustainable exploitation of the biological resources, and enhancing the full valuation of forest goods and services (Poudyal et al. 2018). However, SFM is suffering from a variety of obstacles related to: (1) governance issues (e.g., poorly defined tenure and resource rights, inadequate transparency and accountability, corruption, and limited involvement of relevant actors in the formulation of management plans); (2) economic issues (e.g., high opportunity cost of maintaining forests, high transaction cost for better forest management, low financial returns from improved forest management, and unattractive incentives); (3) regulatory and legislative issues (e.g., poor regulatory framework, lack of political will and incentive to implement regulations, and unrealistic legislation); and (4) knowledge and capacity issues (e.g., poor understanding on the benefits to improve forest management, inadequate financial and material resources, and limited human resources to enforce and monitor regulations) (Chia et al. 2020). However, researchers and practitioners should not give up the idea, but rather the effort to enhance SFM must be redoubled and refined. Selective logging practices determine the outcome of SFM (Poudyal et al. 2018), thus an important component of SFM is the monitoring of the forest status. Reliable 
and operational systems for monitoring selective logging in tropical forests have to be utilized (Hirschmugl et al. 2017). Such a system should be able to provide an estimate of baseline forest conditions in a spatially explicit fashion, departures from which can be used to assess current and previous trends of forest degradation and deforestation (Verbesselt et al. 2010). Remote sensing, due to its synoptic view and fast coverage, can be used to assess and monitor selective logging over tropical forests (Anwar \& Stein 2012), in a spatially and temporally continuous manner (Banskota et al. 2014), which otherwise requires labor-intensive and time-consuming field surveys, that are costly and difficult to undertake (Andersen et al. 2014). Accurate and precise detection of selectively logged sites in a forest is crucial for analyzing the spatial distribution of forest disturbances and degradation (Anwar \& Stein 2012). The remote sensing methods that have been developed to detect selective logging in tropical forests only detect more intensive timber harvest $\left(>20 \mathrm{~m}^{3} \mathrm{ha}^{-1}\right)$, that create large canopy gaps and a variety of spectrally distinct features (e.g., log landing decks and large road networks), thus medium spatial resolution datasets like Landsat are normally considered too coarse to detect less intensive selective logging (Hethcoat et al. 2018). Pinagé et al. (2016) shows that the intensity of canopy impacts may vary according to the selective logging activity, ranging from skid trails to log decks which had the lightest and the heaviest canopy impacts, respectively. High intensity logging causes high forest damage that is long-lasting, and detectable on satellite imagery, and vice versa. Soil fraction images obtained from spectral mixture modeling of multispectral or hyper-spectral data serves as a suitable approach for the detection of selective logging (Souza et al. 2005, Matricardi et al. 2010). While forests with obvious selective logging have well defined logging infrastructure and extensive canopy degradation, forests where subtle selective logging is taking place normally show less canopy perforation or visible infrastructure, and as such remote sensing techniques may not easily differentiate them from undisturbed forest (Asner et al. 2004). Methods required in monitoring selective logging at high temporal resolution are not available. Some of the existing methods for mapping selective logging mostly come with numerous false detections, and existing techniques for minimizing them either impairs the temporal accuracy or increases the omission error for the forest disturbance (Hamunyela et al. 2016). The amount of degradation by selective logging overlooked using currently available techniques is unknown (Hethcoat et al. 2018). New change detection approaches will definitely improve the detection of selective logging in order to achieve accurate mapping and quantification of forest loss (Hamunyela et al. 2016).

Over the last decades, there has been a rapid growth in the number of studies that investigated the use of remote sensing for selective logging (Hethcoat et al. 2018). Providing an overview of the remote sensing data and techniques that have been used in selective logging to identify the challenges and opportunities is essential. Such overview would be useful practically in forest management and scientifically through highlighting the priorities and remaining research gaps for further investigation. Several review studies have been done to analyze the application of remote sensing in mapping deforestation and forest degradation in tropical forests. Solberg et al. (2008) gives an overview of the state of the art of remote sensing techniques, detailing the relevant sensors and algorithms, usable datasets and information on the leading institutions for research and development on techniques that might lead to operational monitoring of tropical forests. Miettinen et al. (2014) critically discussed available approaches for large area forest degradation monitoring with satellite remote sensing data at high to medium spatial resolution, in Southeast Asia. Da Ponte et al. (2015) provided an overview of the remote-sensing-based studies of tropical forest dynamics in Latin America, categorizing the existing studies based on selected sensors and data analysis methodologies. The review has considered both large-scale as well as small-scale forest changes solely induced by anthropological activities. Mitchard (2016) provides a review of earth observation (EO) methods for detecting and measuring forest change in the Tropics. The study basically describes current and emerging EO technologies, and how these can be used to map forests and forest changes. Hirschmugl et al. (2017) reviews the current state of the art in remote sensing based monitoring of forest disturbances and forest degradation. This review article's focus is in Europe's temperate forests and Africa's tropical evergreen forests, using optical EO data. Mitchell et al. (2017) overview is about current remote sensing approaches to monitoring forest degradation in support of countries measurement, reporting and verification (MRV) systems for reducing emissions from deforestation and forest degradation, conservation of existing forest carbon stocks, sustainable forest management and enhancement of forest carbon stocks (REDD+). The paper reviews forest degradation that leads to canopy gaps which are detectable using remote sens-

Tab. 1 - Information extracted from the literature on the remote sensing techniques applied in detecting and monitoring selective logging in tropical forests.

\begin{tabular}{|c|c|}
\hline Attribute & Description \\
\hline Publication details & The year of publication, journal type and national affiliation of the authors and co-authors. \\
\hline Reference data & How reference data used for model calibration and validation was collected. \\
\hline Geographical location & $\begin{array}{l}\text { Location of the study area. If no location was given in the paper, Google Maps was used to determine the } \\
\text { approximate location, or Landsat WRS2 reference was used to identify the center location of the Landsat } \\
\text { footprint used in the analysis. }\end{array}$ \\
\hline Sensor & The sensor type used in the study. \\
\hline Platform & The platform of the sensor, i.e., space-borne, air-borne, or un-manned aerial vehicle. \\
\hline Spatial properties & $\begin{array}{l}\text { The sensor resolution used: coarse resolution }(>100 \mathrm{~m}) \text {, medium resolution }(10-100 \mathrm{~m}) \text {, high resolution }(5-10 \mathrm{~m}) \\
\text { and very high resolution }(<5 \mathrm{~m}) \text {; spatial scale of the studies. }\end{array}$ \\
\hline Temporal properties & $\begin{array}{l}\text { The temporal resolution of the sensor, and temporal scale of the remote sensing data (single date, bi-temporal, } \\
\text { multi-temporal, or time series analysis), and sensor archive. }\end{array}$ \\
\hline Spectral properties & $\begin{array}{l}\text { The spectral properties used in the analysis: Vegetation Index (if a single vegetation index or band was used, } \\
\text { then the index name was noted), Multi (if multi-spectral bands or multiple spectral indices were used), Hyper (if } \\
\text { hyper-spectral bands or multiple narrow-band indices were used), Lidar, and SAR. }\end{array}$ \\
\hline Techniques & The techniques employing satellite data used to detect and quantify selective logging. \\
\hline Accuracy measure & $\begin{array}{l}\text { The measure of accuracy reported in the study. If more than one measure was used, this review preferred } \\
\text { overall accuracy over producer's and user's accuracies, and the coefficient of determination }\left(R^{2}\right) \text { over the root } \\
\text { mean square error (RMSE), respectively. }\end{array}$ \\
\hline Accuracy & Level of accuracy, according to accuracy measure. \\
\hline
\end{tabular}


ing, taking into consideration both forests within and outside the tropics. Therefore, a comprehensive overview of the methods used in detecting and monitoring selective logging in the tropical forests is lacking. In addressing the shortfall, this review paper will have the main focus laid on types of sensors and methodologies of data analysis, and the major challenges and further research needed to explore the use of remote sensing in monitoring small scale forest disturbance due to selective logging in tropical forests. The analyses will concentrate on the period 1992-2019.

\section{Review framework and methodology}

\section{Database search}

The peer-reviewed articles published between 1992 and 2019 were searched in the web-based databases ScienceDirect ${ }^{\oplus}$, Web of Science ${ }^{\circledast}$, and Scopus ${ }^{\circledast}$. They contain the largest abstract and citation databases of peer-reviewed literature, and the University of Wisconsin-Madison rates ScienceDirect $^{\circledast}$, Web of Science ${ }^{\circledast}$, and Scopus ${ }^{\circledast}$ among the top ten web-based databases (UW Madison Labraries 2019). The two most well-established databases that cover the widest scope of English-language literature, while focusing on peer-reviewed publications are Scopus ${ }^{\circledast}$ and Web of Knowledge $^{\circledast}$ (Kleinschroth et al. 2016). Neither database is inclusive, but complements each other.

We used the key terms ("Selective Logging" OR "Canopy Gap" OR "Canopy Opening" OR "Deforestation" OR "Forest Degradation" OR "Forest Disturbance") AND "Tropical Forests" AND "Remote Sensing" in title, abstracts and the key words in the search. We found 5546 articles in ScienceDirect, and 2395 in Web of Science, and 888 articles in Scopus (as of June 20, 2019). Bibliographies of the articles were iteratively scanned until no new relevant articles were identified. All abstracts were scrutinized to filter out irrelevant articles. The remaining articles were read and retained only if they were relevant. Articles with irrelevant titles were excluded. After bringing the relevant articles together, the abstracts of 328 articles were read through. Finally, information was extracted from 110 relevant articles that explicitly discussed the remote sensing of selective logging in tropical forests.

\section{Content analysis}

For the selected 110 articles, the same set of attributes for analysis was extracted (Tab. 1). In particular, noted were publication details, reference data availability, and the geographical location of the study area (i.e., if the study was conducted within the tropics). To characterize the sensor applied in each study, the name of the sensor, properties, and also the platform were recorded. The image processing techniques used to detect and quantify the ar-

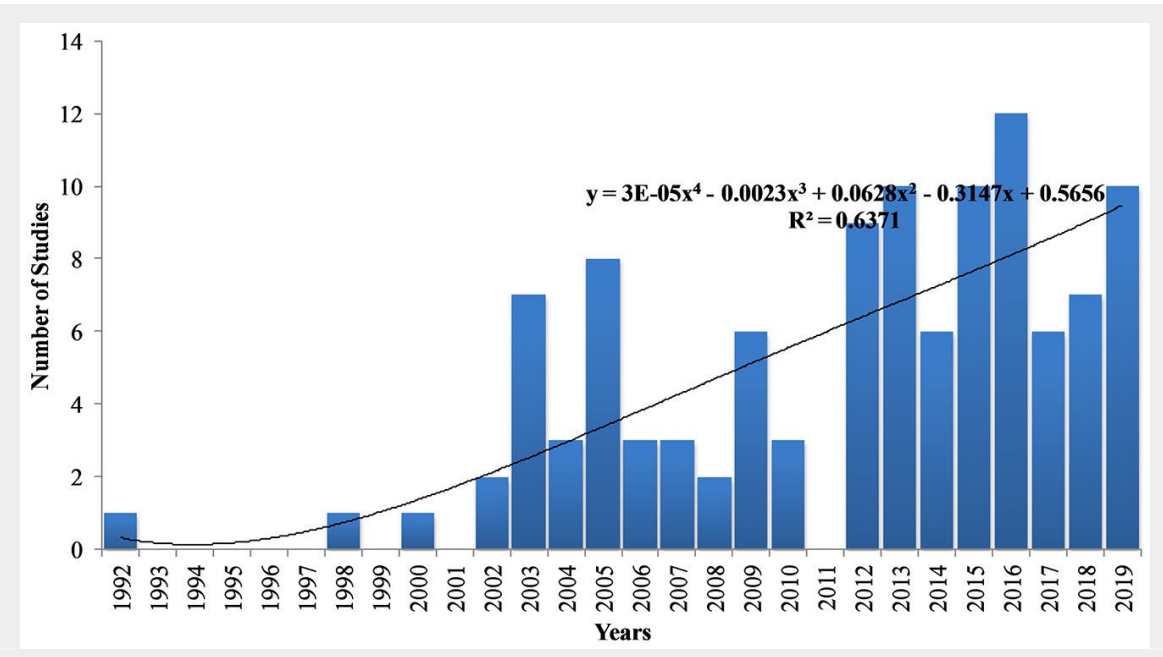

Fig. 1 - Temporal distribution of published articles where remote sensing has been used to analyze selective logging in tropical forests.

eas under selective logging have been discussed. The auxiliary data used, the measure of accuracy and the level of accuracy achieved were also investigated.

\section{Results of literature review}

\section{Publication details}

Watrin \& Rocha (1992) provided some of the first remote sensing estimates of the area affected by selective logging (Souza et al. 2005). After the publication of the second article by Stone \& Lefebvre (1998), the application of remote sensing in selective logging analyses of tropical forests has been rising (Fig. 1). However, no relevant articles were published in 1993-1997, 1999, 2001, and 2011. The first increase in publication activity took place between 2002 and 2010, with an average of four papers per year, while the second considerable increase in publication activity occurred between 2012 and 2019, with an average of nine articles per year. This shows that publication activity has more than double between 2012 and 2019. This could be related to availability of information, awareness about remote sensing technology and growing attention around monitoring of selective logging and related activities in

tropical forests.

The results from the content analysis have shown that using remote sensing to examine selective logging in tropical forests is being accepted by a rising number of scientific disciplines; the articles are published in about fifty different scientific journals. About half of publications are appearing in journals specifically focusing on remote sensing applications (Souza \& Barreto 2000, Souza et al. 2003, 2005, Asner et al. 2005, Koltunov et al. 2009, Matricardi et al. 2010, 2013, Heiskanen et al. 2015, Dalagnol et al. 2019), while the other half is distributed among other journal categories (Asner et al. 2004, Furusawa et al. 2004, Burivalova et al. 2015, Ellis et al. 2016, Sofan et al. 2016). The distribution between the journal categories has articles published in information and communication technology, ecological, cartography, interdisciplinary and natural hazards oriented journals.

The majority of the articles' first authors have been affiliated with institutions located in Europe (De Wasseige \& Defourny 2004, Rahm et al. 2013, Wang et al. 2018), North America (Stone \& Lefebvre 1998, Wang et al. 2005, Ellis et al. 2016), South America (Souza et al. 2003, Graça et al. 2015, Condé et al. 2019), and Asia (Furu-

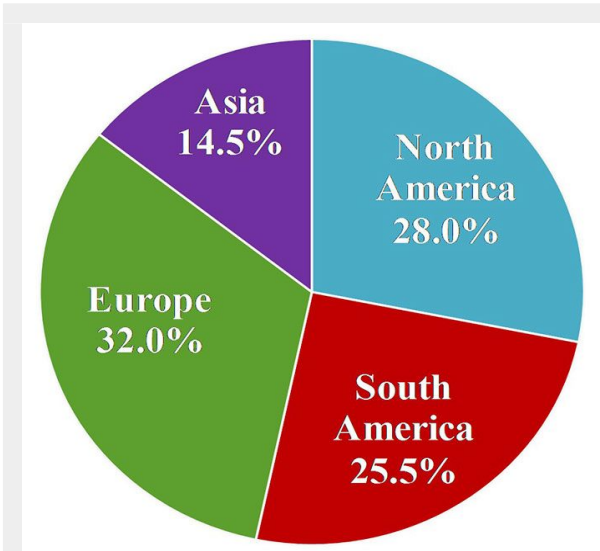

Fig. 2 - Affiliation of lead authors in published articles where remote sensing has been used to analyze selective logging in tropical forests. 
Tab. 2 - Distribution of researchers in remote sensing of selective logging in tropical forests.

\begin{tabular}{lcclcclcc}
\hline Country & $\begin{array}{c}\text { Lead } \\
\text { author }\end{array}$ & Co-author & Country & $\begin{array}{c}\text { Lead } \\
\text { author }\end{array}$ & Co-author & Country & $\begin{array}{c}\text { Lead } \\
\text { author }\end{array}$ & Co-author \\
\hline USA & 26 & 120 & France & 2 & 16 & PNG & 0 & 2 \\
\hline Brazil & 26 & 85 & Austria & 2 & 7 & Norway & 0 & 1 \\
\hline Italy & 7 & 35 & Netherlands & 2 & 7 & Laos & 0 & 1 \\
\hline UK & 6 & 30 & F. Guiana & 2 & 5 & Cameroon & 0 & 1 \\
\hline Germany & 6 & 18 & Mexico & 1 & 5 & Laos & 0 & 1 \\
\hline Finland & 6 & 9 & Switzerland & 1 & 2 & Brunei & 0 & 1 \\
\hline Japan & 5 & 14 & China & 1 & 0 & Bolivia & 0 & 1 \\
\hline Australia & 4 & 9 & Malaysia & 1 & 1 & Argentina & 0 & 1 \\
\hline Indonesia & 4 & 9 & Puerto Rico & 0 & 3 & Madagascar & 0 & 1 \\
\hline Canada & 3 & 6 & Singapore & 0 & 3 & S. Africa & 0 & 1 \\
\hline Belgium & 3 & 1 & Peru & 0 & 2 & Nepal & 0 & 1 \\
\hline
\end{tabular}

sawa et al. 2004, Sofan et al. 2016, Qu et al. 2018). Institutions in Africa do not have any representation (Fig. 2). Only $0.7 \%$ of the articles have African co-authorship (Burivalova et al. 2015, Descals et al. 2017, Kankeu et al. 2016).

Overall, 510 researchers from Universities and research institutions around the World appear in the 110 articles (Tab. 2). The United States of America has 146 researchers who are from American universities and research institutions. The most featured institutions are Michigan State University (Matricardi et al. 2005, 2007, 2010), Carnegie Institution of Washington, Stanford University (Asner et al. 2004, Broadbent et al. 2008), Woods Hole Research Center (Laporte \& Lin 2003, De Grandi et al. 2015) and United States Department of Agriculture (USDA) Forest Service (Andersen et al. 2014). Brazil has contributed 111 researchers. Universities or research institutions hosting researchers at the time a study was being conducted and/or published, determined which countries those researchers were listed under. Eraldo A.T. Matricardi, for example, is listed under USA because he published an article (Matricardi et al. 2007) on selective logging while at Department of Geography, Michigan State University. In Matricardi et al. (2013), the same author is listed under Brazil because at the time of the publica-

tion of the article he was at Department of Forestry, University of Brasilia.

\section{Geographical information}

We tried to establish location of the study areas within the tropical region, where latitude and longitude coordinates were indicated. In case there were no latitude and longitude coordinates provided in the paper, Google Maps $^{\text {TM }}$ was used to find out the approximate location, or Landsat World Reference System 2 (WRS2) was used to spot the center location of the Landsat scene used in the analysis. As seen in Fig. 3, the scientific activities' geographic distribution is uneven in the tropical forests. Significantly more research has been done in South America, and about eightynine per cent has occurred in the Brazilian Amazon, specifically in Pará, Rondônia and Mato Grosso states, where most of the disturbance has taken place. In Asia, majority of the research has been done in Kaliman$\tan$ (Borneo), while in Africa research has been conducted in Cameroon, the African country with the highest percentage of previously logged forests than its Congo Basin neighbors since it has a higher population density (De Grandi et al. 2015).

\section{Sensors used to assess selective logging} in tropical forests

Overall, twenty-six different sensors were
Fig. 3 - Spatial distribution of studies where remote sensing has been used to analyze selective logging in tropical

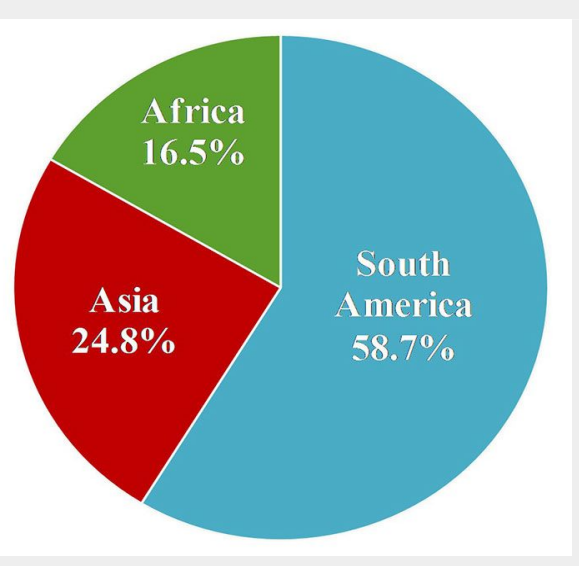

used by the studies reviewed. Optical, radar (radio detection and raging), and lidar (light detection and raging) are identified as the three types of EO data, each with different characteristics. A significant number of articles utilized optical sensors (Fig. 4a), such as the Landsat sensor (Costa et al. 2019), while others used the RapidEye (Franke et al. 2012, Deutscher et al. 2013), IKONOS (Read et al. 2003, Furusawa et al. 2004), Satellite Pour l'Observation de la Terre (SPOT)-4 (Guitet et al. 2012, Sofan et al. 2016), and SPOT-5 (Pithon et al. 2013). Very high resolution and high resolution data were usually utilized as a single dataset or in conjunction with Landsat imagery as reference data. GeoEye-1 (Dalagnol et al. 2019), QuickBird (Hirschmugl et al. 2014), Pleiades (Langner et al. 2018), and the Chinese-Brazil Earth Resources Satellite 2B (CBERS-2B) High Resolution Camera (HRC) (panchromatic, $2.5 \mathrm{~m}$ resolution - Anwar \& Stein 2012) were basically used as reference data. Wang et al. (2005) used IKONOS 1-m pansharpened imagery to validate canopy fractional cover maps resulting from Landsat Enhanced Thematic Mapper Plus $(\mathrm{ETM}+)$ data. In the published articles, the most recent Sentinel-2 (Lima et al. 2019), Advanced Spaceborne Thermal Emission and Reflection Radiometer (ASTER Broadbent et al. 2006), the MODerate Resolution Imaging Spectroradiometer (MODIS - Neba et al. 2014), and SmallSat (Descals et al. 2017) were also used to detect selective logging in tropical forests. Lima et al. (2019) used Sentinel-2 and Landsat-8 Operational Land Imager (OLI) images for Monitoring Selective Logging in the Brazilian Amazon. Landsat 8 detected $36.9 \%$ more area of selective logging than Sentinel-2 data. Logging infrastructure was better mapped from Sentinel-2 (43.2\%) than Landsat 8 (35.5\%) data. Neba et al. (2014) reports that selective logging reduces aboveground biomass (AGB) stock, and through linear regression modeling discovered that logging roads and normalized difference vegetation index (NDVI) values derived from MODIS $250 \mathrm{~m}$ can indirectly determine AGB logged. Unmanned 
aerial vehicles (UAV) were used to acquire digital aerial photographs (DAPs - Ota et al. 2019), and lidar data (Englhart et al. 2013, Kent et al. 2015, Melendy et al. 2018). Qu et al. (2018) estimated leaf area index (LAl) from lidar height percentile metrics and compared it with MODIS product in a selectively logged tropical forest area in Eastern Amazonia. Wedeux \& Coomes (2015) employed airborne laser scanning (ALS) data to measure the canopy of oldgrowth and selectively logged peat swamp forest across a peat dome in Central Kalimantan, Indonesia. The tropical areas are usually characterized by high cloud cover, thus radar sensors that can infiltrate clouds have been favored in many cases (Fig. 4b). Rauste et al. (2013) developed a technique to map selective logging in northern Republic of Congo using ALOS PALSAR imagery acquired before and after the logging activities, and attained an overall accuracy of $70.4 \%$. The same technique was applied for TerrSAR-X data, and achieved an overall accuracy of $53.6 \%$. Lei et al. (2018) developed a new approach using TanDEM-X data to detect and quantify selective logging events in Tapajos National Forest, south of Santarem, Pará in the Brazilian Amazon region. A comparison of TanDEM-X results with ALOS-2 data qualitatively match, confirming both the location and the epoch of the disturbance event. In the assessment of selective logging in tropical forests, a majority of the studies used medium spatial resolution sensors (52.2\%), followed by very high resolution sensors (28\%), high resolution sensors (18\%), and coarse resolution (1.8\%).

In relation to the sensors and area covered by each study, Monteiro et al. (2003) used Landsat Thematic Mapper (TM) and Enhanced Thematic Mapper Plus (ETM+) to detect area affected by logging in three study areas covering $900 \mathrm{~km}^{2}$, located in Sinop, Cláudia and Marcelndia in the state of Mato Grosso, Brazil. Field data was used to test the accuracy of the spectral mixture models to estimate the total area affected by logging (recent, old and repeated). Marcelndia reported the greatest accuracy (80\%), followed by Cláudia ( $73 \%$ ) and Sinop (69\%). The lowest area affected by logging was reported in Sinop (10,731 ha), followed by Marcelndia (19,391 ha) and Cláudia ( 25 $276 \mathrm{ha}$ ). Souza et al. (2003) mapped forest canopy damage associated with logging and burning in a study site approximately $1600 \mathrm{~km}^{2}$ in Paragominas, northeast of Pará, and achieved an overall accuracy of $86 \%$ of the forest degradation map (nonforest, degraded forest, and logged forest). As well, high correlation $\left(R^{2}=0.97\right)$ was observed between the total live AGB of degraded forest classes and the nonphotosynthetic vegetation (NPV) fraction image. The NPV fraction improved the ability to map old selectively logged forests. Matricardi et al. (2007) used Landsat TM and ETM+ and applied visual interpretation and a textural algorithm to identify and

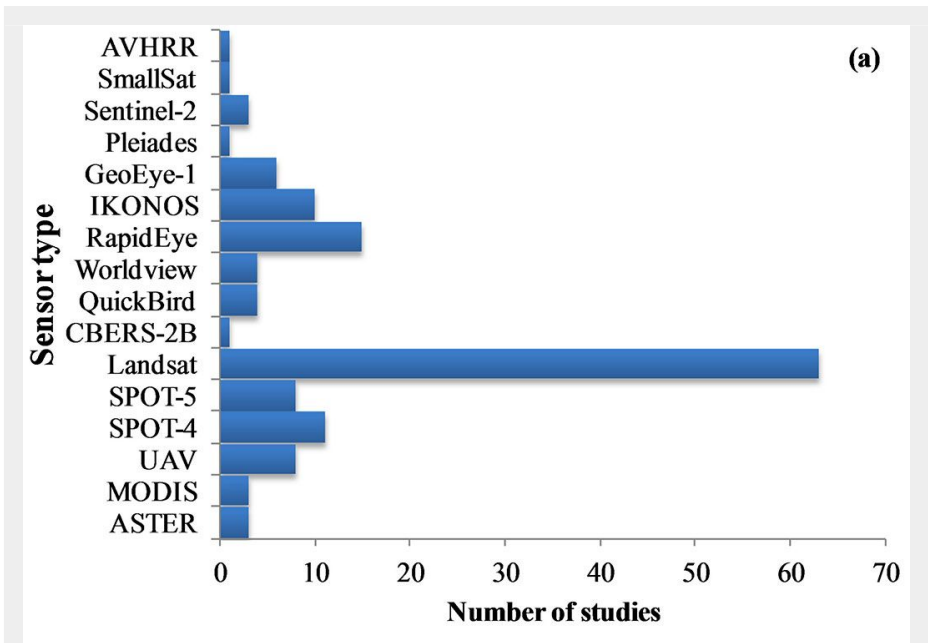

Fig. 4 - Sensors used to assess selective logging in tropical forests. (a) Frequency of optical sensors; (b) frequency of radar sensors.

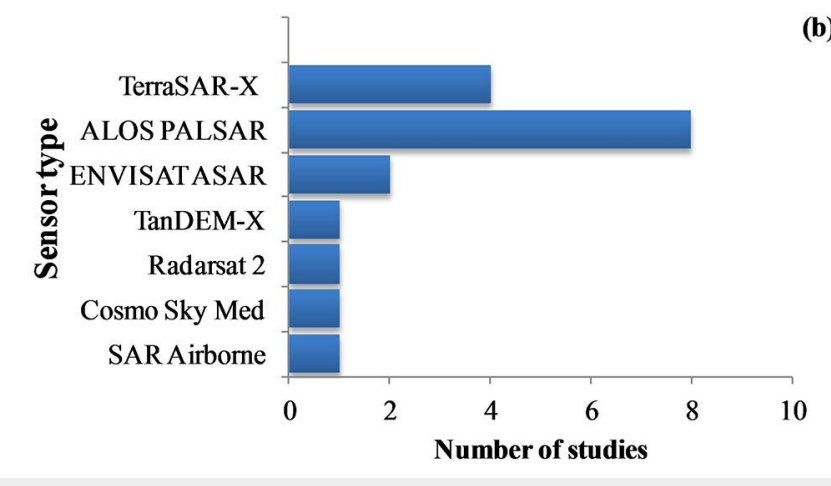

(b)

map selectively logged forests in a study site, approximately $1,300,550 \mathrm{~km}^{2}$ in Brazil's Legal Amazon. The results indicated that by 1992 about $5980 \mathrm{~km}^{2}$ of forest had been logged, and during the 1992-1996 and 19961999 periods the logged area expanded by 10,064 and $26,085 \mathrm{~km}^{2}$, respectively. Visual interpretation and semi-automated techniques showed almost the same overall accuracy of $92.8 \%$ and $90.2 \%$, respectively. Visual interpretation and semi-automated techniques combined produced an overall classification accuracy of $92.9 \%$. In a study site covering about $4700 \mathrm{~km}^{2}$ in a remote area of tropical peat swamp forest in Central Kalimantan, Indonesia, Franke et al. (2012) detected logging activities and the impact of fire by a pixel-based spectral mixture analysis. Forest, non-forest and logging trails could be differentiated with an overall classification accuracy of $91.5 \%$. Baldauf (2013) using TerraSAR-X detected the locations of extracted trees in a study site covering about $300 \mathrm{~km}^{2}$ in Caracaraí municipality, federal state Roraima, Northern Brazil, with an overall accuracy of $98.25 \%$. Sofan et al. (2016) applied a spectral index derived from Landsat ETM+ and SPOT-4, the Normalized Difference Fraction Index (NDFI), then compared it with the Normalized Burn Ratio (NBR) and NDVI, in order to have an enhanced detection of forest canopy damage caused by selective logging activities and associated forest fires in West Kalimantan, especially in Kapuas Hulu and Sintang districts The study site covered about $100,000 \mathrm{~km}^{2}$. The authors found that
NDFI has higher accuracy (95\%) to classify the degradation forest due to logging and burning activities.

Other studies used the coefficient of determination $\left(R^{2}\right)$ as an overall measure of accuracy. Asner et al. (2004) in a study site covering about $450 \mathrm{~km}^{2}$ in Fazenda Cauaxi and Paragominas Municipality of Pará State, Brazil used Landsat ETM+ to assess landscape and regional dynamics of canopy damage following selective logging (forest canopies, exposed non-photosynthetic vegetation, and soils). Spectral mixture analyses of the Landsat ETM+ data show that the spectral mixture model applied in this study, together with a combination of field- and image-derived spectral end member bundles ( $\left.0.74 \leq R^{2} \geq 0.96\right)$, provides a lot of information about forest canopy damage due to selective logging. Souza et al. (2009) in a study covering 62 Transects (each $0.5 \mathrm{ha}$ ) within five regions of the Brazilian Amazon, used Landsat ETM+ and SPOT-4 to detect and map the extent of forest degradation based on canopy damage and small clearings. A high correlation $\left(R^{2}=0.7134\right)$ showed the relationship between AGB and NDFI values for degraded forest of Paragominas (Pará) and Sinop (Mato Grosso). Matricardi et al. (2013) used Landsat TM and ETM+ to survey forest degradation due to selective logging activities and forest fires in Acre, Amapá, Rondónia, and Roraima states, plus parts of Mato Grosso, Maranháo, and Tocantins. The entire study site covered approximately $1,574,350 \mathrm{~km}^{2}$. Empirical linear relationship 
between fractional coverage values derived from each vegetation index and those calculated from hemispherical photographs acquired in the field showed that the modified soil-adjusted vegetation index (MSAVI) presented the highest value of the coefficient of determination $\left(R^{2}\right)$ for Rondônia and Acre study sites (0.74 and 0.81, respectively). MSAVI and $M S A V I_{a f}$ showed the best overall performance under clearsky conditions for the Mato Grosso, Rondônia, and Acre study sites. However, MSAVI showed the best performance under smoky conditions for the Mato Grosso study site (Matricardi et al. 2010). Based on these results, the authors also selected $M S A V I_{a f}$ as the optimum vegetation index to be used in this basin-wide analysis.

\section{Spatial scale}

Throughout the articles reviewed, only local and regional spatial scales have been utilized to examine selective logging in tropical forests. Local scale defines a study covering a relatively small area in a region or country. Regional studies differ in scale, considering not only broader areas such as part of or the entire Amazon in Brazil, but also a study covering an entire country. The local scale studies were more frequent and constituted eighty-five per cent of the articles published (Wang et al. 2005, D'Oliveira et al. 2012, Antropov et al. 2015, Grecchi et al. 2017, Ota et al. 2019), while only fifteen per cent of the studies monitored selective logging at a regional scale (Asner et al. 2005, Broadbent et al. 2008, Matricardi et al. 2013, Langner et al. 2018).

\section{Temporal scale}

As far as the temporal scale of the studies is concerned, it can be concluded that detecting selective logging in tropical forests is achieved through use of single date (composite image), bi-temporal, multi-temporal and time series data analyses. Our analysis shows that about ten per cent of the studies utilized single date analysis. Read et al. (2003) merged 1-m and 4-m resolution IKONOS data to evaluate and monitor logging impacts, north of the Rio Amazon near Itacoatiara, Amazonas. Wang et al. (2005) acquired one scene of Landsat ETM+ on June 18, 2000 to measure forest degradation caused by selective logging in the Amazonian state of Mato Grosso, Brazil. A linear mixture model was applied in the optimal vegetation index domain, the MSAVI to derive tropical forest fractional cover, and to study the capability to detect selective logging in an area which consisted of clear-cut areas, undisturbed forests, and degraded forests (Wang et al. 2005). The canopy fractional cover maps derived from ETM+ imagery were validated with 1-m pan-sharpened IKONOS imagery. Tangki \& Chappell (2008) used a Landsat 5 TM acquired in March 1997 so as to quantify mean tree biomass across selectively logged forest in the Ulu Segama Forest Reserve, Borneo. The results indicated a ma- jor difference in the stand biomass from $172 \mathrm{t} \mathrm{ha}^{-1}$ in a forest area that had high-lead logging to $506 \mathrm{t} \mathrm{ha}^{-1}$ in a similarly sized area of undisturbed forest. Anwar \& Stein (2012) used a Landsat-5 TM image acquired on 21 July, 2008 to detect changes in forest canopy due to selective logging in southwestern Brazilian Amazon.

Thirty-one per cent of the studies used bitemporal data analysis. Asner et al. (2002) used two Landsat-7 ETM+ scenes acquired on July 13, 1999 and July 31, 2000 to quantify the extent and intensity of selective logging and the canopy closure, years after logging operations in Fazenda Cauaxi, Pará State. Andersen et al. (2014) applied a simple differencing of 2010 and 2011 lidar canopy height models to identify areas where canopy over $30 \mathrm{~m}$ tall had been removed in natural tropical forests in the Western Brazilian Amazon. Pinagé et al. (2019) used airborne lidar in 2012 and 2014 to determine the areas with canopy gaps caused by reduced-impact selective logging (RIL) in a forest in Eastern Brazilian Amazon. Bi-temporal analysis detects selective logging in forests by comparing two remote sensing datasets obtained at different points in time (Da Ponte et al. 2015).

About thirty-four per cent of studies applied multi-temporal analysis. Qi et al. (2002) made use of Landsat ETM+ images which were acquired in 1992, 1996, and 2000 to map and quantify selective logging in the Amazon State of Mato Grosso, Brazil. The results were validated using an IKONOS image acquired on the June 13 , 2000. Souza et al. (2003) used a one multispectral SPOT-4 scene acquired in August of 1999, and four Landsat TM images acquired in 1988, 1991, 1995 and 1996, to assist in the identification of forest degradation age in mapping forest canopy damage associated with logging and burning in the Paragominas study. The resultant forest degradation map, with an overall accuracy of $86 \%$, showed $35 \%$ of the forest area as intact forest, $56 \%$ as logged forest and $9 \%$ of the forest area was classified as degraded forest. In order to assess old selectively logged forests and old burned forests at "Fazenda Agrosete" in the Paragominas logging center, north-east of Pará state, Souza \& Roberts (2005) applied four Landsat TM images acquired in 1984, 1988, 1991 and 1996 and one SPOT-4 image acquired in 1999. Matricardi et al. (2013) estimates showed that about 5467, 7618, and 17,437 $\mathrm{km}^{2}$ were new areas of selective logging and/or forest fires in 1992, 1996, and 1999, respectively, and $2.4 \%$ and $1.3 \%$ of the total detected selectively logged and burned forests, respectively, took place within protected areas. Sofan et al. (2016) applied spectral indices analysis on Landsat-7 ETM+ data acquired on July 23, 2006, May 7, 2007, August 5, 2008, July 31, 2009, and SPOT-4 data dated July 31, 2009, May 16, 2012, and October 15, 2012 to enhance detection of forest canopy gaps due to selective logging activities and associated forest fires in West Kalimantan, Indonesia. Unlike bi-temporal analysis, multi-temporal assessments constitute longer time periods which allow quantification of selectively logged areas, as well as offering information concerning the status of the forest ( $\mathrm{Da}$ Ponte et al. 2015). The remaining twentyfive per cent comprise the time series analysis. De Wasseige \& Defourny (2004) developed an operational system in order to detect and monitor selective logging activities in a study which took place in the Ngoto forest, south-western part of the Central African Republic, using time series of six SPOT multi-spectral (from December 95 to July 96) and two Landsat-TM (November 1990 and January 1995) images. The study concluded that despite rapid canopy closure, more than $50 \%$ of the logging roads and skid trail surface network was still visible five years after the last timber extraction, and the spatial resolution of the images played a major role as soon as the contrast between trails and the forest disappeared. Asner et al. (2005) applied an automated remote sensing technique to map selective logging in the Brazilian Amazon, using Landsat ETM+ imagery from 1999 to 2002. Matricardi et al. (2005) estimated the area affected by logging in the Sinop region, State of Mato Grosso, Brazil by applying annual time-series analysis based on 11year series of Landsat imagery from 1992 to 2002. The study showed that, due to rapid regrowth and deforestation, evidence of logging activities normally vanished in a period of 1 to 3 years. Koltunov et al. (2009) present a large-scale study of the relationships between selective logging and forest phenology using a time-series analysis of MODIS satellite data of selectively logged forests in Mato Grosso, Brazil. The time series analysis shows that selective logging leading to about 5-10\% canopy damage contributed a remarkable $54 \%$ of all year 2000 logging observations. Generally, low level of logging intensity causes low forest damage and, therefore, it contributes to short-lived forest phenology changes, while high intensity logging causes high forest damage that is long-lasting and detectable on satellite imagery (Pinagé et al. 2016). Souza et al. (2013) using annual Landsat imagery from 2000 to 2010, quantified degradation and deforestation rates in the Brazilian Amazon over a period of 10 years. The results showed a major decline of annual deforestation rates by $46 \%$ at the end of 2005 and a $20 \%$ increment of annual forest degradation. Based on radar sensors, Antropov et al. (2015) evaluated the use of bi-temporal mosaics of ALOS PALSAR data collected in 2007 and 2010 in order to detect and monitor selective logging activities in northern part of the Republic of the Congo. In a second study, a time series of strip-map C-band SAR data was assessed. The technique involved the analysis of textural features of SAR backscatter temporal log-ratio image. This is the first demonstration of C-band 
SAR based mapping of selectively logged areas. Verhegghen et al. (2015) utilized a time series analysis of SPOT-4 and RapidEye images covering the North of the Republic of Congo, acquired in the period from February to June 2013 to assess forest degradation from selective logging. The analysis highlights very rapid changes in the forest cover, as most logging gaps varnished a span of a few months. Different from bi-temporal analysis, time series can provide a quasi-continuous history of selective logging and regeneration processes (Da Ponte et al. 2015). The detection of selective logging signals using remote sensing is difficult and they are rapidly lost within a very short time due to vegetation regrowth, and this is why time factor is very crucial in detecting selective logging in tropical forests (Hirschmugl et al. 2014).

\section{Methods employed to map and}

characterize selective logging in tropical forests

A variety of mapping techniques have been tried and utilized in studies of selective logging in tropical forests (Souza et al. 2013). These techniques differ in their mapping goals, approach, geographic extent, and map accuracies. Visual interpretation of satellite imagery has been widely used in mapping selective logging in tropical forests (Read et al. 2003, Furusawa et al. 2004). Furusawa et al. (2004) evaluated the effects of a selective logging operation in New Georgia Island, Solomon Islands by means of supervised classification and onscreen visual interpretation, in association with detailed field observation. The selectively logged area accounted for $7.4 \%$ of the original forest and thus causing substantial damage. Read et al. (2003) concluded that use of a combination of highresolution satellite images, taken immediately after logging, and detailed field observations may serve as the most useful way of analyzing selection logging. However, visual interpretation is considered to entail more workload and the skills of the interpreter determine the precision of the final product (Da Ponte et al. 2015). A technique often applied in detecting selective logging is the Spectral Mixture Analysis (SMA). In order to map selective logging in the state of Pará, Souza et al. (2003) applied spectral mixture models to calculate fraction images from SPOT-4 imagery, and concluded that more field studies are needed for selective logging assessment in other regions with different types of forests. Soil fraction images acquired through spectral mixture models assist to identify small forest perforations with spatial patterns showing at the sub-pixel scale in remote-sensing imagery (Souza et al. 2003). Selective logging increases fire susceptibility, owing to the large amount of available fuel in the form of slash piles and collateral damage caused by the logging operations (Souza \& Barreto 2000). An index based on SMA known as Normalized Difference Frac- tion Index (NDFI) was proposed by Souza et al. (2005) to enhance detection of forest canopy damage due to selective logging activities and associated forest fires. Analysis of the NDFI data is enabled by a contextual classification algorithm (CCA) that facilitates accurate detection of logging and fire-derived canopy gaps (Souza et al. 2005). Others have used SMA together with geographic information system (GIS) techniques (Souza \& Barreto 2000, Monteiro et al. 2003). Asner et al. (2006) created a measure, Area-Integrated Gap Fraction (AIGF) of canopy damage by converting remotely sensed subpixel fractional changes in canopy cover into spatial estimates of forest canopy gap fraction. Asner et al. (2005) advanced the computational analysis of Landsat ETM+ satellite data using the Carnegie Landsat Analysis System (CLAS) to map degraded forests by selective logging in the Brazilian Amazon with $86 \%$ overall accuracy. This approach provides automated image analysis using atmospheric modeling (entails detection of forest canopy openings, surface debris, and bare soil exposed by forest disturbances) and pattern-recognition techniques. A wide range of spectral variables (Tab. 1) have been used in enhancing detection of selective logging because they are sensitive to vegetation greenness (Souza et al. 2005). Broadbent et al. (2006) used a probabilistic spectral mixture model, i.e., Monte-Carlo spectral unmixing technique (AutoMCU) to generate per-pixel fractional cover estimates of photosynthetic vegetation (PV), non-photosynthetic vegetation (NPV), and soil. Results were compared with the NDVI. NDVI, and the PV and NPV fractions in felling gaps $>400 \mathrm{~m}^{2}$ were distinguishable from unlogged forest values for up to six months after logging, and those $<400 \mathrm{~m}^{2}$ were distinguishable for up to three months after harvest. Matricardi et al. (2013) applied visual interpretation and semi-automated techniques to detect and quantify basin-wide forest canopy damage due to selective logging in the Brazilian Amazon. The semi-automated technique involved an application of a textural algorithm in order to detect patios. A buffer was applied around the patios so as to estimate the amount of forest affected by logging. The authors also used a semi-automated remote sensing technique based on NPV fraction images derived from SMA, to detect burned forest in the Amazon state of Mato Grosso. The results based on Landsat imagery showed a significant rise $(-300 \%)$ of forest degradation by selective logging and burning in the Brazilian Amazon between 1992 and 1999. Souza et al. (2013) used SMA, NDFI and knowledgebased decision tree classification (DTC) to quantify deforestation and degradation (logged and burned forests) in the Brazilian Amazon. Very high spatial resolution SPOT $2.5 \mathrm{~m}$ pixel imagery was used to generate geolocated points to assess the accuracy of the classified images. The study mapped and assessed the accuracy to quantify forest (97\%), deforestation (85\%) and forest degradation ( $82 \%$ ) with an overall accuracy of $92 \%$. The authors concluded that the total forest area that was being degraded by selective logging and fires each year was equal or exceeded the area being deforested, leading to more fragmented landscapes. Sofan et al. (2016) detected forest canopy damage due to selective logging and forest fires in Kapuas Hulu and Sintang districts of West Kalimantan, Indonesia by applying SMA approach and Spectral indices analysis. Landsat-based monitoring is inadequate due to its low spatial resolution (Da Ponte et al. 2015), and in solving this problem other studies have used object-based change detection techniques (Burivalova et al. 2015, Grecchi et al. 2017), trajectory based analysis (Shimizu et al. 2017), and the use of an airborne laser scanner (ALS) which determines the three-dimensional (3D) structure of forest vegetation, and are thus used to estimate AGB or forest structure changes (Englhart et al. 2013, Kent et al. 2015, Pinagé et al. 2019).

\section{Accuracy Assessment}

The selected articles varied so much in the level of detail about the map validation process, as well as on the metrics used to report accuracy. The study area size ranged from about one $\mathrm{km}^{2}$ to analysis done on a regional scale, covering about 4,000,000 $\mathrm{km}^{2}$, but $\sim 34 \%$ of cases $(\mathrm{n}=37)$ dealt areas covering less than or equal to $1000 \mathrm{~km}^{2}$. Only $80 \%$ of the papers reviewed reported the measure of accuracy. All four standard accuracy assessment metrics (overall accuracy, kappa, user's, and producer's accuracy) were reported in $28.2 \%$ cases. Another $\sim 5 \%$ of the cases included only overall accuracy. The accuracies attained when detecting and monitoring selective logging in tropical forests were explored, and the lowest overall accuracy was recorded by Hernández-Gómez et al. (2019), distributed as $13.9 \%$ in Petcacab and Caobas, $14.5 \%$ in Felipe Carrillo Puerto, and $19.1 \%$ in Noh Bec (Yucatan, Mexico). The study site was approximately $1600 \mathrm{~km}^{2}$, and used Landsat ETM+/OLI. Over $68 \%$ of the observed disturbed areas were mis-classified as unlogged pixels in all ejidos, but the CLAS algorithms worked well in detecting forest degradation from logging in other countries of the tropics, such as Brazil (Asner et al. 2005, 2006, Broadbent et al. 2008). Among the highest overall accuracies are $96.7 \%$ and $95.7 \%$ for Sentinel-2 and Landsat 8, respectively in a study by Lima et al. (2019) while mapping forest disturbance caused by selective logging in south of the Brazilian State of Amazonas. The study site was approximately $5625 \mathrm{~km}^{2}$. An assessment on the impacted area by selective logging led to a discovery of 1143 ha and 1197 ha of disturbed forest on Sentinel-2 and Landsat 8 data, respectively. Despite its coarser spatial resolution, Landsat 8 has a good poten- 


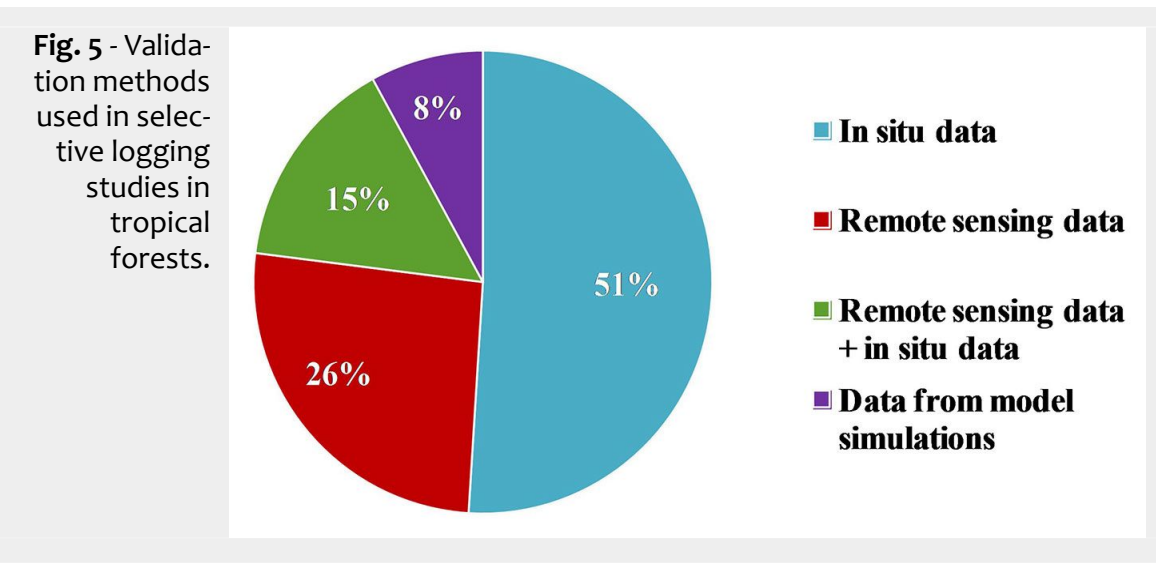

tial to identify logging features. These results agree with a recent study carried out by Hethcoat et al. (2018) in the State of Rondônia, Brazil. However, the area mapped as logged with Landsat 8 data is larger in comparison with Sentinel-2-based results. Sentinel-2 leads to a more precise pixel-based mapping of selective logging due to its higher spatial resolution, making it possible to map smaller disturbances and to map larger disturbances more precisely. In a study site covering about $30,000 \mathrm{~km}^{2}$, Matricardi et al. (2010) in the analysis of selective logging and forest fire impacts on natural forests, attained an overall accuracy of $95.8 \%$ for burned forests detection based on non-photosynthetic vegetation fraction image. Selective logging was found to be responsible for disturbing the largest proportion (31\%) of natural forest, followed by deforestation (29\%). Altogether, selective logging and forest fires affected approximately $40 \%$ of the study site area. Rahm et al. (2013) recorded an overall classification accuracy of $91.5 \%$, $89.7 \%$, $88.9 \%$ on RapidEye data at 5,10 , and $20 \mathrm{~m}$, respectively, while detecting forest degradation in a study site $\left(15,000 \mathrm{~km}^{2}\right)$ in the province of Bandundu in Democratic Republic of Congo. From a forest extent of 34,233 ha on the RapidEye image of 2011, approximately 388 ha were deforested and 267 ha were degraded in August 2012. Costa et al. (2019) applied semi-automatic technique based on texture algorithm and visual interpretation to map selectively logged forests, in portions of the states of Mato Grosso, Pará, and Rondônia. Based on results obtained, it was estimated that the overall accuracies are greater than $91 \%$. The study discovered that forests affected by selective logging increased in Mato Grosso and Rondônia, while a decrease in forests affected by logging activities was observed in Pará.

Qi et al. (2002) used Landsat images to detect selective logging the Amazon State of Mato Grosso, Brazil. Since extensive field measurements are limited due to labor intensity in the tropical areas, the authors used IKONOS image to validate the fractional forest cover estimates. Fractional covers from ETM+ image were plotted against those from IKONOS. The ETM+ and IKONOS fractional cover values fitted well, with $\mathrm{R}^{2}=0.96$. D'Oliveira et al. (2012) mapped forest biomass in areas of low-intensity logging using airborne scanning lidar in Antimary State Forest, Acre State, Western Brazilian Amazon. A systematic random sample of fifty 0.25 -ha ground plots were measured and used to construct lidar-based regression models for AGB $\left(R^{2}=0.72\right)$. The total and mean $A G B$ estimates obtained using the synthetic estimator (total 231,694 Mg; mean 231.7 Mg ha $^{-1}$ ) nearly matched those obtained using the model-assisted estimator (total 231,589 $\mathrm{Mg} \pm 5.477 \mathrm{SE}$; mean $231.6 \mathrm{Mg} \mathrm{ha}^{-1} \pm 5.5 \mathrm{SE}$; $\pm 2.4 \%)$. They were more precise than plotonly simple random sample estimator (total 230,872 Mg $\pm 10,477 \mathrm{SE}$; mean 230.9 Mg $\mathrm{ha}^{-1} \pm 10.5 \mathrm{SE} ; \pm 4.5 \%$ ). Englhart et al. (2013) analyzed multi-temporal lidar and field inventory measurements to study forest dynamics and AGB changes in undisturbed, selective logged and burned peat swamp forests in Borneo. AGB regression models were developed on the basis of field inventory measurements and lidar derived height histograms for $2007\left(R^{2}=0.77\right)$ and $2011\left(R^{2}=0.81\right)$ were quantified, as well as changes in canopy height and AGB. Intact forests had on average $20 \mathrm{t} \mathrm{ha}^{-1} A G B$ with a canopy height increase of $2.3 \mathrm{~m}$ over the four years. Selective logged forests showed an average AGB loss of $55 \mathrm{t} \mathrm{ha}^{-1}$ within $30 \mathrm{~m}^{2}$ and $42 \mathrm{t} \mathrm{ha}^{-1}$ within $50 \mathrm{~m}$ of detected logging trails, although the mean canopy height increased by $0.5 \mathrm{~m}$ and 1.0 $\mathrm{m}$, respectively. Burned forests lost $92 \%$ of the initial biomass. In quantify landscapescale changes in canopy structure due to logging, Wedeux \& Coomes (2015) using airborne laser scanning (ALS) data, applied gap size frequency distributions (GSFDs) in a selectively logged peat, Mawas Conservation Area, Central Kalimantan, Indonesia. This technique was validated, as it yielded a fit going through the origin and with an $\mathrm{R}^{2}$ $=0: 88$ between predicted and measured peat values in 33 plots where peat data were available.

The validation methods used in selective logging studies in tropical forests are field data, remote sensing data, a combination of field data and remote sensing data, and data from model simulations (Fig. 5).

\section{Discussion}

The following section discusses the main findings of this review as well as the emerging needs of further studies on remote sensing techniques applied in detecting and monitoring selective logging in tropical forests. The resultant needs of studies are addressed so as to offer appropriate solutions to guide tropical forest management practices and current research.

\section{Application of remote sensing}

Our analysis shows that that the number of journals publishing remote sensing research has broadened with time in their scientific disciplines, meaning that the remote sensing users have diversified. The publications have shifted from strictly remote sensing oriented journals into journals specialized in forest research, geography, biological conservation, geophysical research, and interdisciplinary science. This suggests that remote sensing is most likely being accepted as dependable information source by a larger group of scientific researchers (Karlson \& Ostwald 2015), who are actively participating in studying tropical forest disturbances. More integration of remote sensing into scientific disciplines dealing with other types of research questions about forest disturbances is required to further promote the scientific involvement of this rapidly developing technology. The need of having improved quality and accessibility of remote sensing data applicable at different spatial scales will possibly facilitate this trend. Improved access to relevant satellite data and best available methods are key to operational forest degradation monitoring (Da Ponte et al. 2015).

Despite steady progress in remote-sensing technologies, the spatial extent, temporal resolution, and availability of data acquired is inadequate to meet the growing demand for information, thus there is need for more accessible, fast, and precise information on the world's tropical forest dynamics. Production of forest disturbance maps is only useful if the stakeholders can access and query the data (Mitchard 2016). An improved availability and accessibility of high- and very-high spatial resolution imagery and development of algorithms able to handle complex data structures will potentially detect and monitor selective logging in tropical forests (Kuemmerle et al. 2013). Deforestation and degradation processes take place daily and on different scales, yet several countries do not have the economical means or governmental support to establish monitoring programmes meant to monitor forest disturbance (Da Ponte et al. 2015). Examples of already implemented programmes are the Brazilian governmental project "Basin Restoration Program" (PRODES), carried out through INPE, monitoring the forests over the Legal Amazon region (Solberg et al. 2008). Complementary to PRODES, since May 2005 , is a near real-time monitoring 
system called Detecção de Desmatamento em Tempo Real (DETER), able to detect forest disturbances larger than 25 ha (Solberg et al. 2008) in a 15-day interval using MODIS and CBERS satellite data. In 2008, a new programme, Mapeamento da Degradação Florestal na Amazônia Brasileira (DEGRAD), was introduced to assess degradation especially from selectively logged activities by using Landsat images and CBERS (Da Ponte et al. 2015). Started in July 2015, MapBiomas is an initiative involving universities, non-governmental organizations (NGOs), and technology companies, including Google, working together to understand Brazilian territory transformations from 1985 to present, based on the annual mapping of land cover land use (Wang et al. 2018). MapBiomass uses Google Earth Engine ${ }^{\circledR}$ to process and distribute satellite images quickly. The platform is open-access, and provides data, codes and methodologies to users, allowing researchers to use MapBiomas's maps and other products (Wang et al. 2018). Such programmes are needed elsewhere within the tropical forests. Ideally, all data, including forest inventory datasets would be made available as open data. This often maximizes the use of the product, leading to innovative users who could not have been envisaged in advance (Mitchard 2016). Thus, open data policies will go a long way in supporting routine monitoring efforts.

\section{Geographic distribution of the scientific activity}

The scientific activities related to forest disturbance due to selective logging in the tropical forests is not evenly distributed. This trend is considerably set by research preferences and investments put in place by institutions within a country, further heightened by the way large international research projects are allocated, and the bilateral associations among national governments and universities (Da Ponte et al. 2015, Karlson \& Ostwald 2015). It can as well be inferred that the shortage of the studies in some tropical regions is due to a lack of expertise in the area. Data gaps mainly exist in developing countries due to inconsistent data acquisition and distribution frameworks, yet it is where deforestation and forest degradation is extensive (Kuemmerle et al. 2013). The areas within the Congo Basin have been experiencing armed conflict, hence researchers are concerned about their security. The low number of authorship with African affiliations is a proof that the research carried out in the tropics has majorly been initiated, conducted and funded by foreign institutions, usually located in Europe (Deutscher et al. 2013, Hirschmugl et al. 2014, Neba et al. 2014) and North America (Laporte \& Lin 2003). Research funding institutions in the United States of America have a very strong presence in the Brazilian Amazon (Souza \& Barreto 2000, Broadbent et al. 2006, Koltunov et al. 2009, Qu et al. 2018,
Dalagnol et al. 2019). Brazilian research funding institutions have also funded several studies in the Brazilian Amazon (Souza \& Barreto 2000, Souza \& Roberts 2005, Condé et al. 2019, Costa et al. 2019, Pinagé et al. 2019). The Brazilian Amazon, being the world's largest contiguous rain forest (Anwar \& Stein 2012), and endowed with high levels of biodiversity and its importance in terms of ecological resources ( $\mathrm{Da}$ Ponte et al. 2015), has obviously attracted more research. This is due to: (i) the fact that the Brazilian Amazon has remarkable rates of forest disturbances, especially Rondônia and Mato Grosso states; (ii) availability of expertise in remote sensing and related technologies; (iii) the influence of government support and awareness; (iv) international interest from the scientific community; and ( $v$ ) availability of financial support to conduct research (Da Ponte et al. 2015).

At present, there is need to increase the study to other regions within tropical areas, such as tropical Africa, which are disadvantaged in remote sensing technology and knowledge. This can be achieved through multilateral research collaborations, readily available in situ data and research infrastructure, and political stability. In areas experiencing social unrest, high resolution imagery may complement in situ data, thus reducing the costs and risks associated with field campaigns. Improved support for capacity building of local research institutions and universities will obviously initiate an increased usage of remote sensing. Remote sensing capacity majorly depends on remote sensing data availability. Currently, a variety of high quality remote sensing data, such as data archive of the Landsat sensor or the highspatial and temporal resolution of the Sentinel satellites, is freely available and in the future it is expected there will be free data of even higher spatial and temporal resolutions.

\section{Sensors used to assess selective logging in tropical forests}

The detection of canopy gaps using moderate resolution remote sensing imagery, e.g., SPOT 4 or Landsat TM present spectral confusion of canopy gaps due to natural disturbance (e.g., windfall) with canopy gaps caused by selective harvesting (Asner et al. 2002), since selective harvest gaps are often sub-pixel in scale (Souza et al. 2005). The spatial resolution of data relative to selective harvest sites creates a scene dominated by mixed (harvest/nonharvest) pixels and the broad spectral range covered by Landsat wavelengths can limit the detection of spectrally subtle changes (Asner et al. 2002). Fusion techniques of panchromatic and multispectral images are commonly applied to enhance the imagery (Read et al. 2003). As well, upscaling of spatial resolution must be performed in some cases of using vegetation indices (Arroyo-Mora et al. 2009).
High spatial resolutions (i.e., 5-10 m pixel size) images are viable for selective logging analysis, since most of the features found in logging environments such as logging roads, log landings, and tree fall gaps can be easily recognized (Antropov et al. 2015). There are satellites (or UAVs or manned aircraft) now collecting data at very high spatial resolutions, up to $31 \mathrm{~cm}$ pixels for Worldview-3, but finer resolution images are expensive and contain computational constraints. As well, locating the boundaries of logged areas by applying visual interpretation on finer resolution images is not easy. Wulder et al. (2008) reports that automated detection of selective logging using very high resolution satellite data has technical challenges, since differences in view-illumination geometries between the pairs of images causes a problem of tree crown geo-location, and the appearance of artifacts due to canopy shadowing can induce misclassification of disturbance. Synthetic aperture radar (SAR), operating at microwave frequencies, is one of the most promising remote sensing methods for the mapping of forest disturbances (Mermoz et al. 2015). The amount of radiation backscattered to the sensor keeps on increasing as the number and/or size of trees present in an area increases, therefore, radar satellites have been used to map aboveground biomass, and degradation (Mitchard 2016). SAR enables imaging in all weather conditions, at any time of day or night, and long-wavelength radar signals can penetrate canopies and have been related to forest structure and woody biomass up to a saturation limit, higher for longer wavelengths (Mermoz et al. 2015). However, despite these advantages, radar has various constraints limiting its application in studying selective logging, for several reasons: the limited SAR data availability, the low data dimensionality for classification algorithms, sensitivity of the SAR signal to surface moisture, and the absence of easy-to-use tools and methods for data interpretation (Whittle et al. 2012).

Lidar data utilizes laser light looking directly down to estimate tree height and structure (Mitchard 2016). Repeat surveys can thus detect the removal of individual trees, and therefore, it is the only remote sensing method that can guarantee to map selective logging with high accuracy, but the applications of present lidar remote sensing sensors for the detection of selective logging, fall short in cost-efficiency, timing, and logistics (Ellis et al. 2016). As well, lidar sensor and mission specifications remain dissimilar, and this affects the level of confidence that is observable about selective logging from the same forest and therefore the assumption behind modelbased inference does not remain valid (Andersen et al. 2014). No lidar satellite is currently collecting data, so lidar can only be obtained through aircraft or UAVs, at high cost (Mitchard 2016).

This review has shown that optical data is 
the most widely used, followed by radar and lidar. This is actually the opposite of their data content, with lidar being the richest source of data since it provides full cross sectional information on forests, while radar provides part of these data, and optical remote sensing systems view only the top of the tree canopy (Mitchard 2016). Data availability, cost, and the complexity of the analysis determine which type of data to use far more than which system would provide the most comprehensive information about a forest. The best method chosen to detect selective logging must strike a balance between accuracy, cost of data and analysis, and optimal monitoring frequency.

Fusing multiple remote sensing sensor platforms is helpful in addressing limitations of some sensors (Mitchell et al. 2017). The combination of optical/SAR can be used for the detection of canopy cover change, while that of SAR/lidar can be used in detecting sub-canopy structural change (Mitchell et al. 2017). This can promote extraction of detailed information. High spatial resolution sensors offer detailed textural information, but have the problem of small area coverage. Moderate spatial resolution sensors have daily or near-daily repeat intervals, but they have less spectral and spatial information (Mitchell et al. 2017). The integration of remotely sensed data from several sensors at a variety of spatial and temporal scales is very useful in estimating forest structure and structural change (Asner et al. 2008). Thus, we expect more sophisticated data fusion techniques in the near future, that can aid in mapping forest disturbance such as selective logging. Obtaining near-coincident data is an uphill task due to little or complete lack of coordination of optical and SAR satellite observations by space agencies. Commitment by space agencies is a key requirement for systematic and coordinated observation of tropical forests on a sustainable basis and with an open data policy (Mitchell et al. 2017). In the near future, there is the need to have technological developments associated with unmanned aerial vehicles to collect and share UAV data at broader scales and minimal costs, with caution to current constraints such as space for taking off, landing, and piloting in thick forest environments. Also the possibility of building and deploying a fleet of high-altitude imaging drones should be explored. Due to the challenges that hamper acquisition of lidar data, the application of ground-based GPS for mapping wall-to-wall infrastructure in similar remote tropical landscapes, is recommended because it can be well integrated into the ground-based monitoring plan required for other impact parameters (e.g., felling inefficiencies), is less vulnerable to time lag errors (old skid trails can be detect on the ground), and remains considerably cheaper (Ellis et al. 2016). Thus, while agreement with GPS-based logging infrastructure maps is promising, more research is required to assess the uncertainties of lidar based logging infrastructure mapping. The integration of lidar remote sensing and forest inventory schemes will reduce the total costs and need for extensive field-based sampling. The innovation of accurate automated methods for processing lidar data could be of critical help because they would lower the data processing costs, allowing for data acquisition of extensive areas while providing repeatable and consistent estimates of vital forest attributes (Melendy et al. 2018).

\section{Multi-temporal monitoring of selective logging}

The majority of the articles reviewed monitored selective logging using bi-temporal and multi-temporal analysis. Relatively, fewer studies utilized the continuous spectral-temporal trajectories for the detection and analyses of selective logging in tropical forests. Mapping and monitoring selective logging requires data with adequate temporal and spatial resolution. As a result of insignificant seasonal changes in dense tropical forests, and the persistent cloud cover for most of the year, the potential benefits of time series analysis plays a key role in the multi-temporal studies (Miettinen et al. 2014). The initial signs of logging activity visible from satellite data vanish in the humid tropics quickly as a result of fast regrowth of secondary vegetation (Langner et al. 2018). Harvest intensity is more directly related to the number of felling gaps, although that relationship may be affected by overlying felling gaps (Broadbent et al. 2006). Canopy openness defines the ability of remote sensors to detect many of the ground disturbances indicative of logging activities (Broadbent et al. 2006). Selective logging at moderately high intensities poses large-scale impacts on the canopy and an abundance of spectrally distinct features like log landing decks or large road networks (Hethcoat et al. 2018). Selective logging at lower logging intensities, e.g., a single tree fall or an under-canopy skid trail, have small-scale impacts on the canopy and can be impossible to detect with moderate spatial resolution imagery where only a small proportion of an imaged pixel is affected by the target feature (Read et al. 2003). Also, some logging impacts such as the loss of green cover associated with a felled tree are ephemeral, and infrequent repeat observation opportunities over cloudy tropical areas make it challenging to detect selective logging (Melendy et al. 2018). Over the last two decades, large-region evaluation of selective logging has been demonstrated with moderate resolution optical imagery (Souza et al. 2005), but with uncertainty resulting from sensor limitations. This promotes the significance of regular data acquisition so as to monitor keenly the temporal changes of reflectance signatures (Miettinen et al. 2014). The fast regrowth vegetation that covers the scars in the canopy is also detectable in satellite data, prolonging the available time for degradation monitoring, but due to the atmospheric conditions within the tropical forests, it has been impossible to obtain continuous time series with high to medium resolution data until very recently (Miettinen et al. 2014).

Fused satellite observations can be utilized in creating a dense time-series to track forest disturbances such as selective logging (Mitchell et al. 2017). This offers a great opportunity to explore the full potential of time series analysis for forest disturbance mapping. Therefore, monitoring logging activities might be enhanced by increasing intra-annual data availability for both medium- and high-spatial resolution sensors (Da Ponte et al. 2015). Dense time series provides a high possibility for monitoring selective logging but requires considerable investment in data processing for it needs extensive computing resources. Methods are required for analyzing dense time series of satellite image time series that provide high spatial details. The opportunity has several challenges and needs new methods that can efficiently handle dense satellite image time series that enable temporal analysis while accounting for a spatial context. This would enable the monitoring of selective logging in tropical forests with unprecedented detail.

Remote sensing can be utilized to develop an early-warning system for imminent forest disturbance events (Verbesselt et al. 2010, Senf et al. 2016) to know whether they are planned or not. Without nearreal time monitoring it means that temporary disturbances occurring between dates remain undetected. Some of the hurdles impeding implementation of near-real time monitoring of tropical forest disturbances might be the often complex pre-processing steps of remote sensing data, lack of ground-truth data, and the often low data availability with high spatial- and mediumspatial resolution sensors (Wulder et al. 2008). However, the recent increase in ready-to-use medium spatial resolution satellite data (i.e., the Landsat surface reflectance higher-level data products), the ability to combine several sensors into one data stream, and the rise in cloud-based processing environments that have many standard disturbance monitoring algorithms already put in place (e.g., Google Earth Engine ${ }^{\circledast}$ ), it is probable that the use of remote sensing for near real-time monitoring of selective logging disturbances will rise drastically in the near future (Senf et al. 2016). Google Earth Engine enables anyone with a web browser to perform extremely large analyses of the earth and its environment.

\section{Remote sensing techniques applied to} selective logging in tropical forests

The need to conduct research on tropical forest degradation emerged in the $1990 \mathrm{~s}$ 
as the spatial extent of selective logging was found to be not accounted for in deforestation studies (Hirschmugl et al. 2014). Various remote sensing methods have been used to detect and estimate the intensity of selective logging in tropical forests, but these methods are less developed (Hethcoat et al. 2018). The majority of remote sensing based research, regarding the monitoring of selective logging in tropical forests uses Landsat imagery, putting into consideration that it is cost-free and acquired in regular intervals (Souza et al. 2013, Mitchard 2016). Most authors (Asner et al. 2002, Shimabukuro et al. 2014) acknowledge they can detect selectively logged areas at moderately high intensities (> $20 \mathrm{~m}^{3} \mathrm{ha}^{-1}$; 3-7 trees ha ${ }^{-1}$ ), but their methods' ability to quantify the extent, lower logging intensities ( $\left.<20 \mathrm{~m}^{3} \mathrm{ha}^{-1}\right)$ and duration of logging damage using Landsat imagery is not known (Hethcoat et al. 2018). Early studies (Laporte \& Lin 2003, Read et al. 2003, De Wasseige \& Defourny 2004, Furusawa et al. 2004) assessed selective logging by visual interpretation on Landsat images. Visual interpretation has been used to quantify clearings in forests and also to identify areas degraded by selected logging activities (Souza et al. 2003, Matricardi et al. 2005). Da Ponte et al. (2015) states that the method is time-consuming and ineffective in quantitative, wall-to-wall assessments of forest disturbance dynamics. The skills of the interpreter determine the precision of the final product. The Spectral Mixture Analysis (SMA) method, although widely used in the Brazilian Amazon, a major challenge with the SMA method by Franke et al. (2012) in Central Kalimantan is that choosing the endmember would have to consider the differences in spectral reflectance as a result of topography and atmospheric conditions, and this limits the use of SMA analyses over large areas. Postclassification method has been used to generate independent classification results from two images acquired in different time periods and then compared pixel-by-pixel (Hirschmugl et al. 2014), or object-by-object (Burivalova et al. 2015). This method can only be used in a bi-temporal data analysis, and therefore it needs multiple bi-temporal comparisons (Da Ponte et al. 2015). Object-based analyses focus on physically meaningful features rather than pixels. This is achieved through image segmentation into individual tree crown (ITC) polygon objects, which reduces the canopy's high local spectral variability, and minimizes the mismatch of tree crown geo-misallocation (Dalagnol et al. 2019). Win et al. (2012) used image differencing method using two SPOT 5 pan-sharpened images acquired in October 2007 and January 2009 to analyze canopy changes from forest harvesting. Other complex methods were developed, such the LandTrendr algorithm, usually applied to a single spectral index or variable, such as Tasseled Cap Wetness (TCW), which is derived from a Tasseled
Cap Transformation, was used as the spectral index because of its sensitivity to disturbance events and water content so as to map selective logging among other forest disturbance activities in Bago mountains, Myanmar (Shimizu et al. 2017).

Remote sensing has shown to be reliable in mapping forest disturbances such as selective logging (Andersen et al. 2014). In detecting selective logging, different algorithms have their own merits. Often, different algorithms are mostly compared to get the best. While localized case studies often provide detailed maps of forest disturbance that are useful for forest management, large scale mapping techniques could offer vital scientific insights (Senf et al. 2016). Presently, the major constraint is the ability to transfer methodologies designed for certain case studies to a wider geographic extent (Senf et al. 2016), and advancement on how to generalize and transfer current approaches will thus assist in carrying out local to regional analysis of forest disturbances such as selective logging (Miettinen et al. 2014). For example, some methods that were designed for the Amazon basin could perhaps be applied in other tropical regions like Africa or the insular Southeast Asia. Examples of such methods are segmentation based automated statistical method for gap detection (Pithon et al. 2013) and combination of spectral mixture analysis (SMA) information into one band, using the Normalized Difference Fraction Index (NDFI) to detect forest areas with canopy damage (Souza et al. 2005). Research of remote sensing techniques applied in monitoring selective logging is still an active topic and innovative techniques are required to effectively apply the increasingly diverse and complex remotely sensed data acquired or projected to be soon acquired from space and airborne sensors.

\section{Accuracy Assessment}

The validation of selective logging maps was mostly achieved through in situ data (Fig. 5), and when it is not available, remote sensing data, data from model simulations, or prior knowledge of the study area by experts of the area were often applied. Even though the alternative methods normally improve the accuracy of the results, in situ data remain as the most reliable method (Souza \& Barreto 2000, Asner et al. 2005, Burivalova et al. 2015, Lei et al. 2018, Lima et al. 2019), but still the collection of sufficient number of reference samples in a dense forest is a serious challenge (Banskota et al. 2014). A reliable validation technique must have an appropriate sampling and response design for selecting and labeling reference samples (Banskota et al. 2014). Forest inventory data are considered inconsistent and are mostly complicated to merge with remote sensing data, due to disparity in plot size and spatial resolution of remote sensing sensors (Senf et al. 2016). In some case accuracy assessment is often avoided since historical reference datasets are in most cases very expensive and rarely available, and the absence of a statistically reliable accuracy assessment interferes with the integrity of selective logging maps (Banskota et al. 2014). Pinagé et al. (2019) doubted that ground-based studies could measure canopy effects as accurately as lidar, thus an explicit groundbased validation for canopy gaps was not conducted. Also, the study did not perform ground-based validation for understory damage and biomass, since it was considered costly. In the case of logging classification, the authors calibrated the model for one sampling epoch and tested the classification for a separate epoch on the same site. The authors plan to validate the classification approach in future studies. After reviewing the elements of accuracy assessment in the published studies, several papers did not provide sufficient detail on how accuracy assessment was performed. The major deficiencies identified were the characterization of the reference data (e.g., in terms of description of sampling unit), the absence of a probability sampling design, and the absence of an error matrix. Lack of transparency in reporting creates credibility issues, interferes with the possibility to compare maps, thus the publication of the set of elements to make accuracy assessment transparent and reproducible is vital in providing remote sensing researchers with the information they need to assess the reliability of new methods and modeling techniques (Morales-Barquero et al. 2019). In thematic mapping with categorical data, accuracy is normally stated as percentages of correctly classified cases for each mapped class by constructing an error matrix (Souza et al. 2003, Matricardi et al. 2010, Hirschmugl et al. 2014, Shimizu et al. 2017), and such accuracy measures are usually estimated from a sample and, thus, are not reliable, making the error matrix increasingly inadequate for full accuracy reporting (Banskota et al. 2014). Dalagnol et al. (2019) used a LiDAR map as a reference to validate very high resolution imagery. Hethcoat et al. (2018) assessed the performance of Random Forest (RF) models using ten-fold cross-validation based on randomly sampled database subsets (which were split into 75\% for training and $25 \%$ was withheld for validation), then threshold value of classification was applied to the validation data and the associated error rates were determined. It is a general assumption that accuracy will depend on the level of information extracted from an imagery, as well as its pixel size. However, we did not find any association between the overall accuracy and the logging intensity mapped, independent from the size of the study area.

To better combine field and inventory data with remote sensing data, researchers should publicly archive their field data upon publication, overtly including spatial metadata, and researchers and managers 
participating in new inventories or field campaigns could incorporate remote sensing in their campaign designs (Senf et al. 2016). For future work to guarantee appropriate interpretation of remote sensing data calls for standardized field data collection, acquired over larger areas and in plots that consider forest disturbance dynamics and what temporal and spatial disturbances can or will be captured on these plots (Senf et al. 2016). An improved availability and accessibility of high- and veryhigh spatial resolution imagery notably will promote the creation of high-quality reference datasets for calibrating remote sensing models of logging disturbances, however, the data must be made accessible to researchers at low costs (Olofsson et al. 2014).

\section{Conclusion}

In spite of several initiatives for monitoring selective logging in tropical forests, mapping the areal extent or impacts of selective logging utilizing remote sensing imagery remains a challenge. Selective logging is a key contributor to the economic, social, and ecological dynamics of tropical regions. The long history of selective logging in tropical forests, spanning several decades, makes them ideal study systems when assessing the long-term effects of selectively logged areas and to notify future management decisions. Nevertheless, logging impacts differ widely, making generalization, as well as policy implementation, difficult. We establish that a variety of methods and sensors are especially important for monitoring selective logging in tropical forests. While our review documents a significant increase in studies mapping selective logging in recent years, we also identified several challenges which require improvement:

- Forest monitoring programmes to assess degradation especially from selectively logged activities, are needed elsewhere within the tropical forests.

- Improved quality and accessibility of remote sensing data applicable at different spatial scales would lead to more diversification of remote sensing users.

- More integration of remote sensing into scientific disciplines dealing with other types of research questions about degradation by selective logging so as to further the scientific involvement of this rapidly developing technology.

- There is need to increase scientific activities related to selective logging to other regions within tropical areas, such as tropical Africa, which are disadvantaged in remote sensing technology and knowledge.

- More sophisticated data fusion techniques are expected in the near future, that can be more effective in mapping degradation by selective logging.

- Commitment by space agencies for systematic and coordinated observation of tropical forests on a sustainable basis and with an open data policy.

- Technological developments associated with unmanned aerial vehicles to collect and share UAV data at broader scales and minimal costs are needed.

- The innovation of accurate automated methods for processing LiDAR data could be of critical help because they would lower the data processing costs, allowing for data acquisition of extensive areas while providing repeatable and consistent estimates of vital forest attributes.

- Affordable and reliable methods are required for analyzing dense time series of satellite image time series that provide high spatial details.

- Improvement on how to generalize and transfer approaches designed for certain case studies to a wider geographic extent will assist in carrying out local to regional analysis of selective logging.

- More research on remote sensing techniques applied in monitoring selective logging are required to effectively apply the increasingly diverse and complex remotely sensed data acquired or projected to be acquired from space and airborne sensors.

- Researchers should standardized field data collection so as to guarantee appropriate interpretation of remote sensing data.

Solving these concerns in future research can assist integrating remote sensingbased maps into operational forest management, and support an inclusion of selective logging disturbances as integrated processes into local, regional and global ecosystem models.

\section{Acknowledgement}

CJ: conceptualization, methodology, data curation, writing - original draft preparation. EA: supervision, reviewing and editing. Herbert Omari: proof reading of the manuscript.

\section{Funding}

This research did not receive any specific grant from funding agencies in the public, commercial, or not-for-profit sectors.

\section{Competing interests}

The authors have declared that no competing interests exist.

\section{References}

Andersen HE, Reutebuch SE, McGaughey RJ, D'Oliveira MV, Keller M (2014). Monitoring selective logging in western Amazonia with repeat lidar flights. Remote Sensing of Environment 151: 157-165. - doi: 10.1016/J.RSE.2013.08. 049

Antropov O, Rauste Y, Seifert FM, Häme T (2015). Selective logging of tropical forests observed using L- and C-band SAR satellite data. In: Proceedings of the "IEEE International Geoscience and Remote Sensing Symposium (IGARSS)". Milan (Italy) 26-31 July 2015. IEEE Institute of Electrical and Electronics Engineers, Piscataway, NJ, USA, pp. 3870-3873. - doi:
10.1109/IGARSS.2015.7326669

Anwar S, Stein A (2012). Detection and spatial analysis of selective logging with geometrically corrected Landsat images. International Journal of Remote Sensing 33: 7820-7843. - doi: 10.1080/01431161.2012.701378

Arroyo-Mora P, Kalacska M, Chazdon R (2009). Spectral unmixing of forest canopy recovery in selectively logged units in a tropical lowland forest, Costa Rica. In: Anais "XIV Simpósio Brasileiro de Sensoriamento Remoto" [Annals XIV Brazilian Symposium on Remote Sensing]. Natal (Brasil) 25-30 Apr 2009. INPE, São José dos Campos, São Paulo, Brazil, pp. 2539-2546.

Asner GP, Keller M, Pereira R, Zweede JC (2002). Remote sensing of selective logging in Amazonia: assessing limitations based on detailed field observations, Landsat ETM+, and textural analysis. Remote Sensing of Environment 80: 483-496. - doi: 10.1016/So034-4257(01)00326-1 Asner GP, Keller M, Pereira R, Zweede JC, Silva J (2004). Canopy damage and recovery after selective logging in Amazonia: field and satellite studies. Ecological Applications 14: 280-298. doi: 10.1890/01-6019

Asner GP, Knapp DE, Broadbent EN, Oliveira PJC, Keller M, Silva JN (2005). Selective logging in the Brazilian Amazon. Science 310: 480-482. doi: $10.1126 /$ science. 1118051

Asner GP, Broadbent EN, Oliveira PJC, Keller M, Knapp DE, Silva JNM (2006). Condition and fate of logged forests in the Brazilian Amazon. Proceedings of the National Academy of Sciences USA 103: 12947-12950. - doi: 10.1073/pnas.06040 93103

Asner GP, Hughes RF, Vitousek PM, Knapp DE, Kennedy-Bowdoin T, Boardman J (2008). Invasive plants transform the three-dimensional structure of rain forests. Proceedings of the National Academy of Sciences USA 105: 45194523. - doi: 10.1073/pnas.0710811105

Baldauf T (2013). Monitoring reduced emissions from deforestation and forest degradation (REDD+): capabilities of high-resolution active remote sensing. PhD thesis, Biology Department, University of Hamburg, Hamburg, Germany, pp. 94.

Banskota A, Kayastha N, Falkowski MJ, Wulder MA, Froese R, White JC (2014). Forest monitoring using Landsat time-series data - A review. Canadian Journal of Remote Sensing 40: 362384. - doi: 10.1080/07038992.2014.987376 Broadbent EN, Zarin DJ, Asner GP, Peña-Claros M, Cooper A, Littell R (2006). Recovery of forest structure and spectral properties after selective logging in lowland Bolivia. Ecological Applications 16 (3): 1148-1163. - doi: 10.1890/10 51-0761(2006)016[1148:ROFSAS]2.0.CO;2

Broadbent EN, Asner GP, Keller M, Knapp DE, Oliveira PJC, Silva JN (2008). Forest fragmentation and edge effects from deforestation and selective logging in the Brazilian Amazon. Biological Conservation 141: 1745-1757. - doi: 10.101 6/j.biocon.2008.04.024

Burivalova Z, Bauert MR, Hassold S, Fatroandrianjafinonjasolomiovazo NT, Koh LP (2015). Relevance of global forest change data set to local conservation: case study of forest degradation in Masoala National Park, Madagascar. Biotropica 47: 267-274. - doi: 10.1111/btp.12194 Chia EL, Hubert D, Enongene K, Tegegne YT 
(2020). An AHP assessment of barriers in adopting sustainable forest management practices in the context of carbon emission reduc tions in Cameroon. Journal of Sustainable Forestry 39: 379-391. - doi: 10.1080/10549811.20 19.1673180

Condé TM, Higuchi N, Lima AJN (2019). Illegal selective logging and forest fires in the northern Brazilian Amazon. Forests 10: 61. - doi: 10.3390/ f10010061

Costa OB, Matricardi EAT, Pedlowski MA, Miguel EP, Gaspar RO (2019). Selective logging detection in the Brazilian Amazon. Floresta e Ambiente 26: e20170634. - doi: 10.1590/2179-8087.06 3417

Da Ponte E, Fleckenstein $\mathrm{M}$, Leinenkugel $\mathrm{P}$, Parker A, Oppelt N, Kuenzer C (2015). Tropical forest cover dynamics for Latin America using Earth observation data: a review covering the continental, regional, and local scale. International Journal of Remote Sensing 36: 31963242. - doi: 10.1080/01431161.2015.1058539

Dalagnol R, Phillips OL, Gloor E, Galvão LS, Wagner FH, Locks CJ, Luiz EOC, Aragão LE (2019). Quantifying canopy tree loss and gap recovery in tropical forests under low-intensity logging using VHR satellite imagery and airborne lidar. Remote Sensing 11: 817. - doi: 10.3390/rs110708 17

De Grandi EC, Mitchard E, Woodhouse IH, De Grandi GD (2015). Spatial wavelet statistics of SAR backscatter for characterizing degraded forest: a case study from Cameroon. IEEE Journal of Selected Topics in Applied Earth Observations and Remote Sensing 8: 3572-3584. - doi: 10.1109/JSTARS.2015.2420596

De Wasseige C, Defourny P (2004). Remote sensing of selective logging impact for tropical forest management. Forest Ecology and Management 188: 161-173. - doi: 10.1016/j.foreco.2003. 07.035

Descals A, Szantoi Z, Beck P, Brink A, Strobl P (2017). Automated detection of selective logging using Smallsat imagery. IEEE Geoscience and Remote Sensing Letters pp. 1-5. - doi: 10.110 9/LGRS.2017.2720841

Deutscher J, Perko R, Gutjahr K, Hirschmugl M, Schardt M (2013). Mapping tropical rainforest canopy disturbances in 3D by COSMO-SkyMed spotlight InSAR-Stereo data to detect areas of forest degradation. Remote Sensing 5: 648663. - doi: 10.3390/rs5020648

D'Oliveira MVN, Reutebuch SE, McGaughey RJ, Andersen H-E (2012). Estimating forest biomass and identifying low-intensity logging areas using airborne scanning lidar in Antimary State Forest, Acre State, western Brazilian Amazon. Remote Sensing of Environment 124: 479-491. doi: 10.1016/j.rse.2012.05.014

Edwards DP, Tobias J, Sheil D, Meijaard E, Laurance WF (2014). Maintaining ecosystem function and services in logged tropical forests. Trends in Ecology and Evolution 29: 511-520. doi: 10.1016/j.tree.2014.07.003

Ellis P, Griscom B, Walker W, Gonçalves F, Cormier T (2016). Mapping selective logging impacts in Borneo with GPS and airborne lidar. Forest Ecology and Management 365: 184-196. doi: 10.1016/j.foreco.2016.01.020

Englhart S, Jubanski J, Siegert F (2013). Quantifying dynamics in tropical peat swamp forest biomass with multi-temporal lidar datasets. Remote Sensing 5: 2368-2388. - doi: 10.3390/rs505 2368

Franke J, Navratil P, Keuck V, Peterson K, Siegert $F$ (2012). Monitoring fire and selective logging activities in tropical peat swamp forests. IEEE Journal of Selected Topics in Applied Earth Observations and Remote Sensing 5: 1811-1820. doi: 10.1109/JSTARS.2012.2202638

Furusawa T, Pahari K, Umezaki M, Ohtsuka R (2004). Impacts of selective logging on New Georgia Island, Solomon Islands evaluated using very-high-resolution satellite (IKONOS) data. Environmental Conservation 31: 349-355. doi: $10.1017 /$ S0376892904001638

Gibson L, Lee TM, Koh LP, Brooks BW, Gardner TA, Barlow J, Peres CA, Bradshaw CJA, Laurance WF, Lovejoy TE, Sodhi NS (2011). Primary forests are irreplaceable for sustaining tropical biodiversity. Nature 478: 378-381. - doi: 10.1038/ nature10425

Graça PMLA, Maldonado FD, Santos JR, Keizer EWH (2015). Multi-temporal analysis of radiometric changes in satellite images of forest edges to infer selective-logging areas in the Amazon forest. Acta Amazonica 45: 35-44. - doi: 10.1590/1809-4392201401073

Grecchi RC, Beuchle R, Shimabukuro YE, Aragão LEOC, Arai E, Simonetti D, Achard F (2017). An integrated remote sensing and GIS approach for monitoring areas affected by selective logging: a case study in northern Mato Grosso, Brazilian Amazon. International Journal of Applied Earth Observation and Geoinformation 61: 70-80. - doi: 10.1016/j.jag.2017.05.001

Guitet S, Pithon S, Brunaux O, Jubelin G, Gond V (2012). Impacts of logging on the canopy and the consequences for forest management in French Guiana. Forest Ecology and Management 277: 124-131. - doi: 10.1016/j.foreco.2012.04. 011

Hamunyela E, Verbesselt J, Herold M (2016). Using spatial context to improve early detection of deforestation from Landsat time series. Remote Sensing of Environment 172: 126-138. - doi: 10.1016/j.rse.2015.11.006

Heiskanen J, Korhonen L, Hietanen J, Pellikka PKE (2015). Use of airborne lidar for estimating canopy gap fraction and leaf area index of tropical montane forests. International Journal of Remote Sensing 36: 2569-2583. - doi: 10.1080/01 431161.2015.1041177

Hernández-Gómez IU, Cerdan-Cabrera CR, Navarro-Martínez A, Vazquez-Luna D, ArmentaMontero S, Ellis EA (2019). Assessment of the CLASlite forest monitoring system in detecting disturbance from selective logging in the Selva Maya, Mexico. Silva Fennica 53: 1. - doi: 10.14214 /sf.10012

Hethcoat MG, Edwards DP, Carreiras JMB, Bryant RG, França FM, Quegan S (2018). A machine learning approach to map tropical selective logging. Remote Sensing of Environment 221: 569-582. - doi: 10.1016/j.rse.2018.11.044

Hirschmugl MG, Steinegger $M$, Gallaun $H$, Schardt M (2014). Mapping forest degradation due to selective logging by means of time series analysis: case studies in Central Africa. Remote Sensing 6: 756-775. - doi: 10.3390/rs6010 756

Hirschmugl MG, Gallaun H, Dees M, Datta P,
Deutscher J, Koutsias N, Schardt M (2017). Methods for mapping forest disturbance and degradation from optical earth observation data: a review. Current Forestry Reports 3: 3245. - doi: 10.1007/s40725-017-0047-2

Kankeu RS, Sonwa DJ, Atyi R, Nkal N (2016). Quantifying post logging biomass loss using satellite images and ground measurements in Southeast Cameroon. Journal of Forestry Research 27. - doi: 10.1007/s11676-016-0277-3

Karlson M, Ostwald M (2015). Remote sensing of vegetation in the Sudano-Sahelian zone: a literature review from 1975 to 2014. Journal of Arid Environments 124: 257-269. - doi: 10.1016/j.jarid env.2015.08.022

Kent R, Lindsell J, Laurin G, Valentini R, Coomes D (2015). Airborne lidar detects selectively logged tropical forest even in an advanced stage of recovery. Remote Sensing 7: 83488367. - doi: $10.3390 /$ rs70708348

Kleinschroth F, Healey JR, Sist P, Mortier F, Gourlet-Fleury S (2016). How persistent are the impacts of logging roads on Central African forest vegetation? Journal of Applied Ecology 53 (4): 1127-1137. - doi: 10.1111/1365-2664.12661

Koltunov A, Ustin SL, Asner GP, Fung I (2009). Selective logging changes forest phenology in the Brazilian Amazon: evidence from MODIS images time series analysis. Remote Sensing of Environment 113: 2431-2440. - doi: 10.1016/j.rse. 2009.07.005

Kuemmerle T, Erb K-H, Meyfroidt P, Müller D, Verburg $P$, Estel $S$, Haberl $H$, Hostert $P$, Jepsen M, Kastner T, Levers C, Lindner M, Plutzar C, Verkerk H, Zanden E, Reenberg A (2013). Challenges and opportunities in mapping land use intensity globally. Current Opinion in Environmental Sustainability 5: 484-493. - doi: 10.1016/j. cosust.2013.06.002

Langner A, Miettinen J, Kukkonen M, Vancutsem C, Simonetti D, Vieilledent G, Verhegghen A, Gallego J, Stibig H-J (2018). Towards operational monitoring of forest canopy disturbance in evergreen rain forests: a test case in continental Southeast Asia. Remote Sensing 10: 544. - doi: 10.3390/rs10040544

Laporte NT, Lin TS (2003). Monitoring logging in the tropical forest of Republic of Congo with Landsat imagery. In: Proceedings of the "IEEE International Geoscience and Remote Sensing Symposium (IGARSS)". Toulouse (France) 21-25 July 2003. IEEE Institute of Electrical and Electronics Engineers, Piscataway, NJ, USA, pp. 2565-2567. - doi: 10.1109/IGARSS.2003.1294510

Lei Y, Treuhaft R, Keller M, Dos-Santos M, Gonçalves F, Neumann M (2018). Quantification of selective logging in tropical forest with spaceborne SAR Interferometry. Remote Sensing of Environment 211: 167-183. - doi: 10.1016/j.rse.20 18.04.009

UW Madison Labraries (2019). Top 10 Databases. University of Wisconsin-Madison Libraries, WI, USA, web site. [online] URL: http://www.libra ry.wisc.edu/find/top-10-databases/

Lima TA, Beuchle R, Langner A, Grecchi R, Griess VC, Achard F (2019). Comparing Sentinel-2 MSI and Landsat $8 \mathrm{OLI}$ imagery for monitoring selective logging in the Brazilian Amazon. Remote Sensing 11: 961. - doi: 10.3390/rs11080961 Matricardi EAT, Skole DL, Cochrane MA, Qi J, Chomentowski W (2005). Monitoring selective 
logging in tropical evergreen forests using Landsat: multitemporal regional analyses in Mato Grosso, Brazil. Earth Interactions 9: 1-24. doi: 10.1175/El142.1

Matricardi EAT, Skole DL, Cochrane MA, Pedlowski M, Chomentowski W (2007). Multi-temporal assessment of selective logging in the Brazilian Amazon using Landsat data. International Journal of Remote Sensing 28: 63-82. doi: 10.1080/01431160600763014

Matricardi EAT, Skole DL, Pedlowski MA, Chomentowski W, Fernandes LC (2010). Assessment of tropical forest degradation by selective logging and fire using Landsat imagery. Remote Sensing of Environment 114: 1117-1129. - doi: 10.1016/j.rse.2010.01.001

Matricardi EAT, Skole DL, Pedlowski MA, Chemontowski W (2013). Assessment of forest disturbances by selective logging and forest fires in the Brazilian Amazon using Landsat data. International Journal of Remote Sensing 34: 10571086. - doi: 10.108o/01431161.2012.717182

Melendy L, Hagen SC, Sullivan FB, Pearson TRH, Walker SM, Ellis P, Kustiyo Sambodo AK, Roswintiarti $\mathrm{O}$, Hanson MA, Klassen AW, Palace MW, Braswell BH, Delgado GM (2018). Automated method for measuring the extent of selective logging damage with airborne lidar data. ISPRS Journal of Photogrammetry and Remote Sensing 139: 228-240. - doi: 10.1016/J.IS PRSJPRS.2018.02.022

Mermoz S, Réjou-Méchain M, Villard L, Le Toan T, Rossi V, Gourlet-Fleury S (2015). Decrease of L-band SAR backscatter with biomass of dense forests. Remote Sensing of Environment 159: 307-317. - doi: 10.1016/j.rse.2014.12.019

Miettinen J, Stibig HJ, Achard F (2014). Remote sensing of forest degradation in Southeast Asia: aiming for a regional view through 5-30 m satellite data. Global Ecology and Conservation 2: 24-36. - doi: 10.1016/J.GECCO.2014.07.007 Mitchard ETA (2016). A review of earth observation methods for detecting and measuring forest change in the tropics. Ecometrica, Edinburgh, UK, pp. 2-4.

Mitchell AL, Rosenqvist A, Mora B (2017). Current remote sensing approaches to monitoring forest degradation in support of countries measurement, reporting and verification (MRV) systems for REDD+. Carbon Balance Management 12: 9. - doi: 10.1186/s13021-017-007 8-9

Monteiro A, Souza CM, Barreto P (2003). Detection of logging in Amazonian transition forests using spectral mixture models. International Journal of Remote Sensing 24: 151-159. - doi: 10.1080/01431160305008

Morales-Barquero L, Lyons MB, Phinn SR, Roelfsema CM (2019). Trends in remote sensing accuracy assessment approaches in the context of natural resources. Remote Sensing 11: 2305. doi: $10.3390 /$ rs 11192305

Neba CS, Kanninen M, Atyi R, Sonwa D (2014). Assessment and prediction of above-ground biomass in selectively logged forest concessions using field measurements and remote sensing data: case study in South East Cameroon. Forest Ecology and Management 329: 177-185. - doi: 10.1061/j.forec02014.06.018

Nellemann C (2012). Green carbon, black trade. Illegal logging, tax fraud and laundering in the
World's tropical forests. A rapid response assessment. INTERPOL Environmental Crime Programme, Arendal , United Nations Environment Programme and GRID-Arendal, Birkeland Trykkeri AS, Spelefjellveien 1, 4760 Birkeland, Norway, pp. 1. [online] URL: http://wedocs.unep. org/handle/20.500.11822/8030

Olofsson P, Giles MF, Herold M, Stehman S, Curtis EW, Wulder M (2014). Good practices for assessing accuracy and estimating area of land change. Remote Sensing of Environment. 148: 42-57. - doi: 10.1016/j.rse.2014.02.015

Ota T, Ahmed OS, Minn ST, Khai TC, Mizoue N, Yoshida S (2019). Estimating selective logging impacts on aboveground biomass in tropical forests using digital aerial photography obtained before and after a logging event from an unmanned aerial vehicle. Forest Ecology and Management 433: 162-169. - doi: 10.1016/j.for eco.2018.10.058

Pinagé ER, Matricardi EAT, Leal FA, Pedlowski MA (2016). Estimates of selective logging impacts in tropical forest canopy cover using RapidEye imagery and field data. iForest 9: 461468. - doi: 10.3832/ifor1534-008

Pinagé ER, Keller M, Duffy P, Longo M, Dos-Santos MN, Morton DC (2019). Long-term impacts of selective logging on Amazon forest dynamics from multi-temporal airborne lidar. Remote Sensing 11: 709. - doi: 10.3390/rs11060709

Pithon S, Jubelin G, Guitet S, Gond V (2013). A statistical method for detecting logging-related canopy gaps using high-resolution optical remote sensing. International Journal of Remote Sensing 34: 700-711. - doi: 10.1080/01431161.2012. 706719

Poudyal BH, Maraseni T, Cockfield G (2018). Evolutionary dynamics of selective logging in the tropics: a systematic review of impact studies and their effectiveness in sustainable forest management. Forest Ecology and Management 430: 166-175. - doi: 10.1016/j.foreco.2018.08.006 Qi J, Wang C, Matricardi E, Skole D (2002). Improved selective logging detection with Landsat images in tropical regions. In: Proceedings of the "IEEE International Geoscience and Remote Sensing Symposium (IGARSS)". Toronto (Ontario, Canada) 24-28 June 2002. IEEE Institute of Electrical and Electronics Engineers, Piscataway, NJ, USA, pp. 2078-2080. - doi: 10.1109/ IGARSS.2002.1026450

Qu Y, Shaker A, Silva AC, Klauberg C, Pinagé ER (2018). Remote sensing of leaf area index from lidar height percentile metrics and comparison with MODIS product in a selectively logged tropical forest area in eastern Amazonia. Remote Sensing 10: 970. - doi: 10.3390/rs10060970 Rahm M, Van Wolvelaer J, Vrieling A, Mertens B (2013). Detecting forest degradation in the Congo Basin by optical remote sensing. In: Proceedings of the "ESA Living Planet Symposium”. Edinburgh (Scotland, UK) 9-13 Sept 2013. ESA, Noordwijk, The Netherlands, pp. 19.

Rauste R, Antropov O, Häme T, Ramminger G, Gomez S, Seifert FM (2013). Mapping selective logging in tropical forest with space-borne SAR data. In: Proceedings of the "ESA Living Planet Symposium”. Edinburgh (UK) 9-13 Sept 2013. ESA, Noordwijk, The Netherlands, pp. 168-173.

Read JM, Clark DB, Venticinque EM, Moreira MP (2003). Application of merged 1-m and 4-m res- olution satellite data to research and management in tropical forests. Journal of Applied Ecology 40: 592-600. - doi: 10.1046/j.1365-2664.200 3.00814.x

Senf C, Wulder M, Campbell E, Hostert P (2016). Using Landsat to assess the relationship between spatiotemporal patterns of western spruce budworm outbreaks and regional-scale weather variability. Canadian Journal of Remote Sensing 42: 706-718. - doi: 10.1080/07038 992.2016.1220828

Shimabukuro YE, Beuchle R, Grecchi RC, Achard $F$ (2014). Assessment of forest degradation in Brazilian Amazon due to selective logging and fires using time series of fraction images derived from Landsat ETM+ images. Remote Sensing Letters 5: 773-782. - doi: 10.1080/215070 4X.2014.967880

Shimizu K, Ahmed OS, Ponce-Hernandez R, Ota T, Win ZC, Mizoue N, Yoshida S (2017). Attribution of disturbance agents to forest change using a Landsat time series in tropical seasonal forests in the Bago Mountains, Myanmar. Forests 8: 218. - doi: 10.3390/f8060218

Sofan P, Vetrita Y, Yulianto F, Khomarudin MR (2016). Multi-temporal remote sensing data and spectral indices analysis for detection tropical rainforest degradation: case study in Kapuas Hulu and Sintang districts, west Kalimantan, Indonesia. Natural Hazards 80: 1279-1301. doi: 10.1007/s11069-015-2023-0

Solberg R, Malnes E, Amlien J, Danks F, Haarpaintner J, Hgda K-A, Johansen BE, Karlsen SR, Koren $\mathrm{H}$ (2008). State of the art for tropical forest monitoring by remote sensing: a review carried out for the Ministry for the Environment of Norway and the Norwegian Space Centre. Norwegian Computing Centre, Oslo, Norway, pp. 11.

Souza CM, Barreto P (2000). An alternative approach for detecting and monitoring selectively logged forests in the Amazon. International Journal of Remote Sensing 21: 173-179. - doi: 10.1080/014311600211064

Souza CM, Firestone L, Silva LM, Roberts D (2003). Mapping forest degradation in the eastern Amazon from SPOT 4 through spectral mixture models. Remote Sensing of Environment 87: 494-506. - doi: 10.1016/j.rse.2002.08.002

Souza CM, Roberts D (2005). Mapping forest degradation in the Amazon region with Ikonos images. International Journal of Remote Sensing 26 (3): 425-429. - doi: 10.1080/014311603100 0101620

Souza CM, Roberts D, Cochrane MA (2005). Combining spectral and spatial information to map canopy damage from selective logging and forest fires. Remote Sensing of Environment 98: 329-343. - doi: 10.1016/j.rse.2005.07. 013

Souza CM, Cochrane MA, Sales M, Monteiro AL, Mollicone D (2009). Integrating forest transects and remote sensing data to quantify carbon loss due to forest degradation in the Brazilian Amazon. In: Proceedings of the Workshop "Assessment and monitoring of forest degradation”. Rome (Italy) 8-10 Sept 2009. Forestry Department, Food and Agriculture Organization of the United Nations, Rome, Italy, pp. 1-17. Souza CM, Siqueira JV, Sales MH, Fonseca AV, Ribeiro JG, Numata I, Cochrane MA, Barber CP, 
Roberts DA, Barlow J (2013). Ten-year Landsat classification of deforestation and forest degradation in the Brazilian Amazon. Remote Sensing 5: 5493-5513. - doi: 10.3390/rs5115493 Stone TA, Lefebvre P (1998). Using multi-temporal satellite data to evaluate selective logging in Pará, Brazil. International Journal of Remote Sensing 19: 2517-2526. - doi: 10.1080/0143116982 14604

Tangki H, Chappell NA (2008). Biomass variation across selectively logged forest within a 225$\mathrm{km} 2$ region of Borneo and its prediction by Landsat TM. Forest Ecology and Management 256: 1960-1970. - doi: 10.1016/j.foreco.2008.07. 018

Verbesselt J, Hyndman R, Newnham G, Culvenor $D$ (2010). Detecting trend and seasonal changes in satellite image time series. Remote Sensing of Environment 114: 106-115. - doi: 10.1016/j.rse. 2009.08.014

Verhegghen A, Eva H, Achard F (2015). Assessing forest degradation from selective logging using time series of fine spatial resolution imagery in Republic of Congo. In: Proceedings of the "IEEE
International Geoscience and Remote Sensing Symposium (IGARSS)". Milan (Italy) 26-31 July 2015. IEEE Institute of Electrical and Electronics Engineers, Piscataway, NJ, USA, pp. 2044-2047. - doi: 10.1109/IGARSS.2015.7326202

Wang C, Qi J, Cochrane M (2005). Assessment of tropical forest degradation with canopy fractional cover from Landsat ETM+ and IKONOS imagery. Earth Interactions 9: 1-18. - doi: 10.1175/ El133.1

Wang Y, Ziv G, Adami M, Mitchard E, Batterman SA, Buermann W, Marimon BS, Marimon-Junior $\mathrm{BH}$, Reis S, Rodrigues D, Galbraith D (2018). Mapping tropical disturbed forests using multidecadal $30 \mathrm{~m}$ optical satellite imagery. Remote Sensing of Environment 221: 474-488. - doi: 10.1016/j.rse.2018.11.028

Watrin OS, Rocha AMA (1992). Levantamento da vegetação natural e do uso da terra no município de Paragominas (PA) utilizando imagens $\mathrm{TM} /$ Landsat [Survey of natural vegetation and land use in the municipality of Paragominas (PA) using TM/Landsat]. Boletim de Pesquisa 124, EMBRAPA/CPATU, Bele'm, PA, Brazil, pp.
40.

Wedeux BMM, Coomes DA (2015). Landscapescale changes in forest canopy structure across a partially logged tropical peat swamp. Biogeosciences 12: 6707-6719. - doi: 10.5194/bg-12-67072015

Whittle M, Quegan S, Uryu Y, Stüewe M, Yulianto K (2012). Detection of tropical deforestation using ALOS-PALSAR: a Sumatran case study. Remote Sensing of Environment 124: 8398. - doi: 10.1016/j.rse.2012.04.027

Win RN, Suzuki R, Takeda S (2012). Remote sensing analysis of forest damage by selection logging in the Kabaung Reserved Forest, Bago Mountains, Myanmar. Journal of Forest Research 17: 121-128. - doi: 10.1007/s10310-011-0276 $-3$

Wulder MA, White JC, Coops NC, Butson CR (2008). Multi-temporal analysis of high spatial resolution imagery for disturbance monitoring. Remote Sensing of Environment 112: 2729-2740. - doi: 10.1016/j.rse.2008.01.010 